\title{
Análise faciológica da Formação Alter do Chão (Cretáceo, Bacia do Amazonas), próximo à cidade de Óbidos, Pará, Brasil
}

\author{
Anderson Conceição Mendes ${ }^{1}$, Werner Truckenbrod ${ }^{2}$ \& Afonso César Rodrigues Nogueira²
}

\begin{abstract}
Resumo Depósitos cretáceos da Formação Alter do Chão, expostos em barrancos do rio Amazonas, próximos da cidade de Óbidos - PA, são caracterizados por arenitos, conglomeratos e pelitos. Sete litofácies foram reconhecidas que compreendem conglomerado maciço $(\mathrm{Cm})$, arenitos com estratificações acanalada (Aa) e tabular (At), arenito com laminação cruzada cavalgante (Al) e pelitos maciço (PM), bioturbado (PB) e deformado (Pd). Essas fácies, organizadas em ciclos de granodecrescência ascendente, que variam de 1 a $6 \mathrm{~m}$ de espessura, foram agrupadas nas associações preenchimento de canal e depósitos externos ao canal de um sistema fluvial meandrante. O preenchimento de canal envolve barras conglomeráticas, com geometria lenticular a acunhada, compostas das fácies Cm e Aa; formas de leito arenosas, com geometria lenticular, tabular ou acunhada, constituídas pelas fácies Aa, At e Al; e barra de acreção lateral, formada pelas fácies Aa, At e Pm, mas com migração distinta com relação à das formas de leito arenosas. Enquanto as medidas de paleocorrente obtidas das formas de leito arenosas indicam paleofluxo preferencial para SW e subordinado para S, a barra de acreção lateral migra para E/ESE, perpendicularmente ao sentido do paleofluxo principal. Os seguintes depósitos externos ao canal principal foram reconhecidos, baseados em suas relações geométricas: depósitos pelíticos da planície de inundação, inclusive canal abandonado preenchido com pelitos; canal de crevasse, composto das fácies Aa e At; e depósitos de dique marginal, constituído das fácies Aa, Al e Pm. Enquanto o canal abandonado com pelitos se sobrepõe a arenitos, o canal de crevasse está em contato com pelitos da planície de inundação e corta também arenitos finos e pelitos interpretados como depósitos de dique marginal. Lentes pelíticas alinhadas no mesmo nível sobre arenitos, mas com largura menor que a do canal abandonado, são atribuídas a depressões preenchidas, durante enchentes, no topo de barra com acreção lateral.
\end{abstract}

Palavras-chave: Formação Alter do Chão, Análise de fácies, Bacia do Amazonas, Óbidos.

Abstract Faciological analysis of Alter do Chão Formation (Cretaceous, Amazon basin), near the town of Óbidos, Pará, Brazil. Cretaceous deposits of the Alter do Chão Formation, exposed on the banks of the Amazon river, near the town of Óbidos - PA, record a succession of sandstones, conglomerates and mudstones. Seven lithofacies have been recognized which comprise massive conglomerate $(\mathrm{Cm})$, trough cross-bedded sandstone $(\mathrm{St})$, planar cross-bedded sandstone (Sp), climbing cross-laminated sandstone (Sl), massive mudstone (Mm), bioturbated mudstone $(\mathrm{Mb})$ and deformed mudstone $(\mathrm{Md})$. These facies are organized in fining-upward cycles, 1 to $6 \mathrm{~m}$ thick, and have been grouped into two associations: channel fill and overbank deposits belonging to a fluvial meandering system. The channel-fill deposits include lenticular gravel bars composed of facies Cm and St, sandy bedforms with facies St, Sp and Sl, and lateral accretion bar, consisted of facies St, Sp and Mm, but with distinct migration with regard to that of the sandy bed forms. While paleocurrent measurements from facies St and Sp of sandy bedforms indicate a preferred orientation of paleoflow to SW and a subordinate flow to S, the lateral accretion bar migrates to E/ESE. The following overbank elements have been recognized based on their geometric relationships: muddy floodplain deposits including abandoned channel plug, crevasse splay channel filled with facies St and Sp and natural levee deposits composed of facies St, Sl and Mm. While the muddy channel plug overlies sandstones, the crevasse channel fill is in contact with mudstones of the floodplain and also cuts through fine-grained sandstones and mudstones interpreted as natural levee deposits. Adjacent muddy lenses in the same stratigraphic level on sandstone but with smaller width than that of the abandoned channel are attributed to swales, filled during floods, capping lateral accretion bar.

Keywords: Alter do Chão Formation, Facies analysis, Amazon basin, Óbidos.

INTRODUÇÃo Depósitos siliciclásticos da Formação Alter do Chão afloram, na região de Óbidos - PA, em barrancos ao longo do rio Amazonas (Fig. 1). Esses depósitos são constituídos, principalmente, de arenitos bem estruturados, além de conglomerados e pelitos limitados no topo por um paleossolo laterítico de idade paleógena (Boulangé \& Carvalho 1997). Estudos enfocando aspectos sedimentológicos e paleontológicos

1 - Programa de Pós-graduação em Geologia e Geoquímica, Instituto de Geociências, Universidade Federal do Pará, Belém (PA). E-mail: acmendes@ufpa.br

2 - Instituto de Geociências, Universidade Federal do Pará, Belém (PA). E-mail: trucken@ufpa.br, anogueira@ufpa.br 

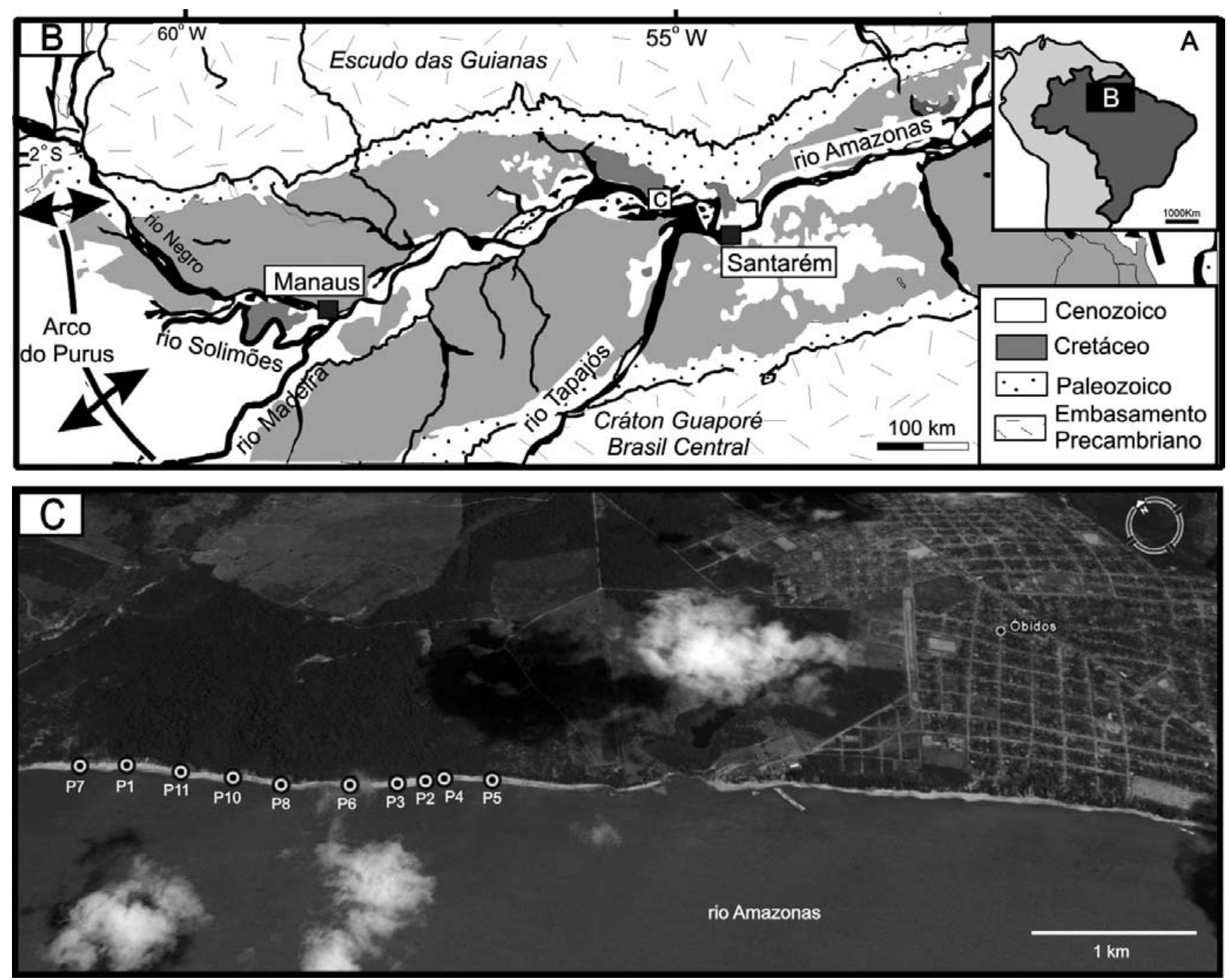

Figura 1 - A-C, Localização da área de estudo, estado do Pará, norte do Brasil. Exposição da Formação Alter do Chão ao longo do rio Amazonas, próxima a Óbidos - PA.

nos depósitos cretáceos da bacia do Amazonas foram abordados, de maneira detalhada, pela primeira vez na ilha de Careiro, próximo de Manaus (Rossetti \& Netto 2006). Esse estudo atribuiu, naquele lugar, influência marinha à Formação Alter do Chão, fato este observado pela primeira vez na literatura, uma vez que tais depósitos tinham sua gênese relacionada com ambiente flúvio-deltáico-lacustre (Kistler 1954, Caputo et al. 1972, Wanderley Filho 1991, Cunha et al. 1994, Dino et al. 1999, Nogueira et al. 1999).

Os objetivos deste trabalho são prover descrição e interpretação detalhada das fácies, elementos arquiteturais e variação no estilo do fluvial para determinação de modelo deposicional para Formação Alter do Chão na região de Óbidos, Pará.

\section{CONTEXTO GEOLÓGICO}

Bacia do Amazonas A bacia do Amazonas é do tipo intracratônica com área de aproximadamente
$500.000 \mathrm{~km}^{2}$, e preenchimento predominante de rochas siliciclásticas, essencialmente paleozoicas, intrudidas no Mesozoico por diques e soleiras de diabásio. Estas rochas atingem espessura máxima de $5.000 \mathrm{~m}$ (Caputo 1984). A bacia tem forma alongada e eixo deposicional orientado W/SW-E/NE, limitada pelos arcos Purus e Gurupa a oeste e leste, respectivamente, bem como pelo Escudo das Guianas, ao norte pelo Escudo Brasiliano a sul.

O tectonismo na bacia é essencialmente rúptil, de pouca expressão vertical, mas com deformações regionais de grande escala, que mantêm relações espaciais estreitas com as principais faixas orogênicas do embasamento, através de processos de reativação ao longo de antigas descontinuidades durante o Fanerozoico (Rezende \& Brito 1973). Segundo Wanderley Filho (1991), as principais falhas NW-SE são de transferência e seccionam quase todas as unidades litológicas e deslocam os depocentros da bacia. Nepomuceno \& 
Theodoro (1985) descreveram três fases de tectonismo, com base em dados de linhas sísmicas, na bacia do Amazonas: a) eventos tectônicos responsáveis pela implantação de falhamentos normais, de idade Permo-Carbonífera, provavelmente ligada à Orogenia Herciniana; b) tectonismo distensivo com intensa atividade ígnea durante o Permo-Triássico, coincidente com a abertura do Atlântico norte; e c) tectonismo transpressivo e transtensivo do Juro-Cretáceo até hoje, aparentemente relacionado à abertura do Atlântico sul.

O preenchimento da bacia durante o Proterozoico é representado pelo Grupo Purus que, em parte, é relacionado à fase rift da bacia do Amazonas (Cunha et al. 1994). Tal grupo é representado pelas formações Prosperança e Acari (Eiras \& Matsuda 1995). No Fanerozoico a bacia do Amazonas é dividida em quatro sequências (Cunha et al. 1994) que são separadas por discordâncias nas bordas e por conformidades na parte central da bacia (Fig. 2). Essas sequências são: Ordoviciano superior-Devoniano inferior (Grupo Trombetas); Devoniano inferior-Carbonífero inferior (Grupo Curuá e Urupadi) e Carbonífero superior-Permiano (Grupo Tapajós). A geração da última sequência, com aproximadamente $500 \mathrm{~m}$ de espessura representada pelo Cretáceo superior-Terciário (Grupo Javari) (Cunha et al. 1994, Eiras et al. 1994) é relacionada a uma extensão leste-oeste associada com a evolução do oceano Atlântico sul e com a cordilheira dos Andes. O Grupo Javari é composto de depósitos flúvio-lacustre-deltáicos das formações Alter do Chão e Solimões, que cobrem grande parte das formações paleozoicas. A Formação Alter do Chão, objeto desse trabalho, é detalhada abaixo.

\section{Formação Alter do Chão}

ASPECTOS GERAIS A Formação Alter do Chão foi primeiramente definida por Kistler (1954) como sendo composta de arenitos avermelhados, argilitos, conglomerados e brechas intraformacionais, tradicionalmente atribuídos a sistemas fluvial e lacustre/deltaico (Daemon 1975).

Esta unidade é relativamente pobre em fósseis, representados por plantas dicotiledôneas na região de Monte Alegre e vértebras de dinossauros (Dino et al. 1999). Em bacias intracratônicas a litologia dominantemente é siliciclástica e a deposição em condições de paleoclima quente com semiaridez dominante, naturalmente restringiam a biota sobrevivente e não ofereciam condições adequadas de preservação fossílifera.

A partir de informações de subsuperfície (dados sísmicos e perfis elétricos), aliadas a informações sedimentológicas e palinoestratigráficas, foram reconhecidas duas sucessões sedimentares na Formação Alter do Chão (Dino et al. 1999): sequência 1 (inferior), caracterizada por influxo de terrígenos associados a um sistema fluvial meandrante que evolui para um sistema anastomosado, com retrabalhamento eólico, de idade neoaptiana/eoalbiana e; sequência 2 (superior), composta de ciclos progradacionais flúvio-deltáicos-lacustre, de idade cenomaniana. Essa sequência contém arenitos avermelhados com icnofósseis e estruturas pedogenéticas (peds, slickensides), atribuídas a silcretes (Nogueira et al. 1999).

Estudos geoquímicos realizados nos arenitos vermelhos da Formação Alter do Chão indicam que houve variações de rocha fontes e mudança na seleção granulométrica durante o transporte, deposição e pedogênese pós-deposicional. Estas variações ocorreram em paleambiente de planícies abandonadas e rios entrelaçados sob condições de clima seco com tendência a úmido durante o Cretáceo na bacia do Amazonas (Horbe et al. 2006).

O contato entre a Formação Alter do Chão e as unidades paleozoicas é representado por uma expressiva discordância erosiva. Na borda norte da bacia, próximo a Manaus, foram caracterizadas, em seções sísmicas, feições evidentes de corte e preenchimento de canais na base dessa formação (Costa 2002). Nesta mesma região, um sistema deltaico, dominado por onda e com influência marinha, tem sido proposto para os depósitos da Formação Alter do Chão (Rossetti \& Netto 2006).

IDADE Depósitos sedimentares pós-paleozoicos na bacia do Amazonas têm sido descritos por diversos autores que atribuíram tanto idades mesozoicas quanto cenozoicas. Moura (1938) correlacionou os sedimentos arenosos aflorantes nas escarpas do rio Amazonas aos depósitos do Grupo Barreiras de idade cenozoica aflorante na região costeira do estado do Pará. A idade cretácea da formação foi, primeiramente, sugerida com base em um dente de Therapoda (Price 1960), e depois datações palinológicas atribuíram idades mesoalbiana e eocenomaniana à porção basal dessa formação e neocenomaniana a turoniana à porção média (Daemon \& Contreras 1971, Daemon 1975), enquanto não há vestígios fossilíferos da porção superior. Posteriormente, trabalhos de mapeamento litoestratigráfico pelo Serviço Geológico do Brasil (CPRM) têm utilizado a idade cretácea obtida pela assembleia de palinomorfos de subsuperfície para todos os depósitos pós-paleozoicos aflorantes da bacia do Amazonas, relacionando-os como Formação Alter do Chão (Petri \& Fúlfaro 1983, Cunha et al. 1994, Dino et al. 1999). Com as recentes descobertas de depósitos de idade miocena na região centro-oeste da bacia do Amazonas por Rozo et al. (2005), os depósitos atribuídos a Formação Alter do Chão tem sido mais bem separados como unidades silicificadas e cauliníticas possivelmente de idade paleógena ou mais antiga. A ocorrência de 


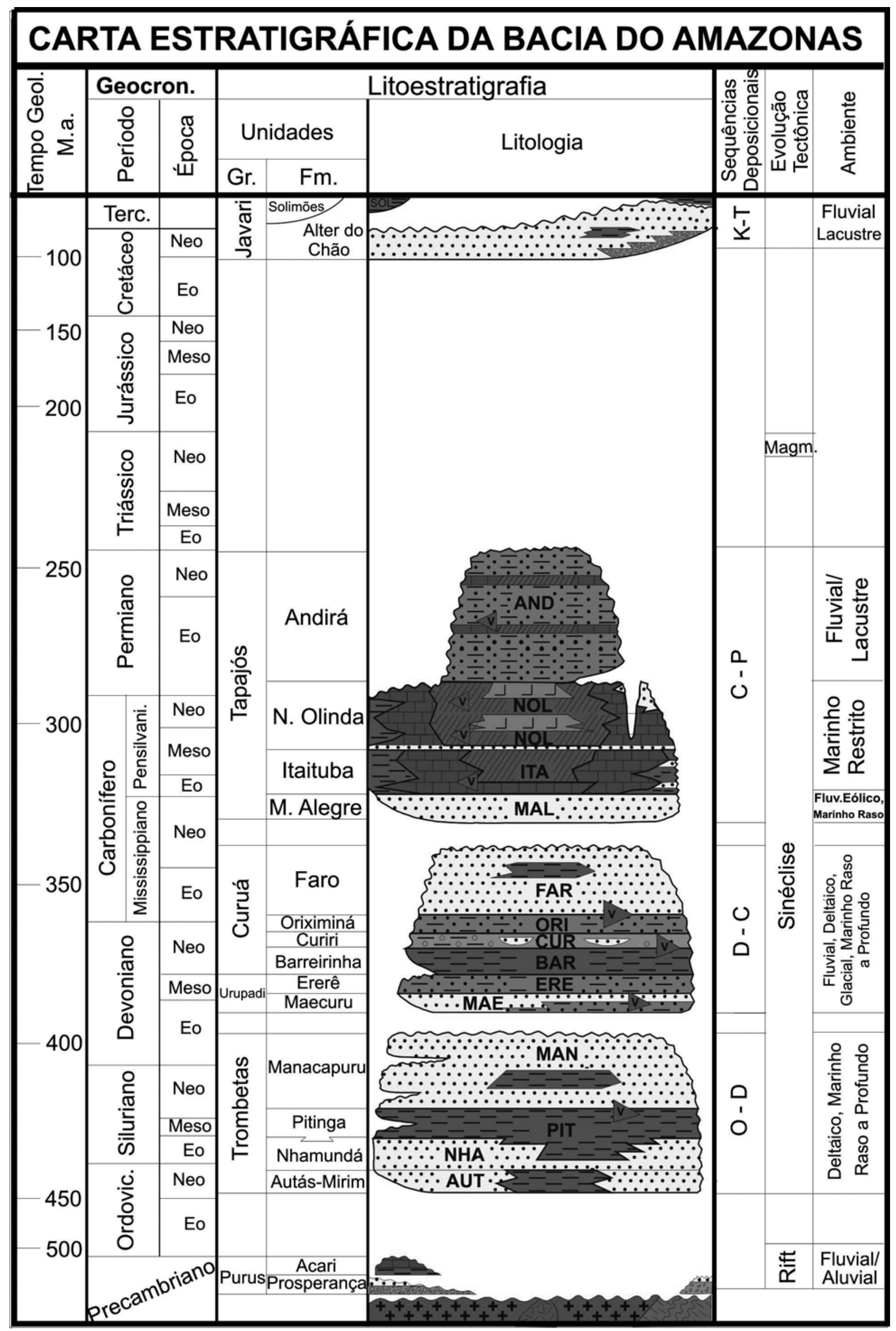

Figura 2 - Carta estratigráfica da bacia do Amazonas. Modificada de Eiras (1998). 
perfis de alteração laterítica, principalmente com horizonte bauxítico, geralmente desenvolvido sobre rochas cretáceas sugere pelo menos idade paleógena para a bauxitização (Truckenbrodt et al. 1982, Boulangé \& Carvalho 1997, Lucas 1997). A dificuldade em datar estas rochas, por palinologia, em superfície deve-se ao fato das exposições ao longo do rio Amazonas encontrarem-se intemperizadas, principalmente pelo desenvolvimento dos perfis laterítico-bauxítico. Assim, a idade da Formação Alter do Chão pode ser inferida como mais antiga que Paleógeno a Cretáceo.

MATERIAIS E MÉTODOS A análise de fácies da Formação Alter do Chão foi baseada na determinação de geometria, textura e estruturas sedimentares, além dos padrões de paleocorrente (Walker 1992, 2006). Depois de identificadas, as mesmas, foram representadas em perfis colunares e seções panorâmicas. As seções panorâmicas foram elaboradas a partir de fotomosaicos, seguindo o trabalho de Arnot et al. (1997).

\section{LITOFÁCIES}

Aspectos gerais Os perfis estudados da Formação Alter do Chão contêm conglomerados, arenitos e pelitos. Foram identificadas sete litofácies (Fig. 3; Tab. 1) que são discutidas com base na classificação de Miall (1985, 1996).

Os arenitos são ricos em grãos de quartzo e com menor frequência ocorrem fragmentos líticos de pelitos, granitos e gnaisses. A granulometria varia de fina a grossa, com grãos angulosos a subarredondados e seleção pobre a moderada. São bastante friáveis e geralmente vermelhos, mas ocorrem também, arenitos esbranquiçados. A matriz é constituída de caulinita, produto de intemperismo do feldspato. Os pelitos apresentam estruturas maciças, bioturbações e deformação. Dominam pelitos de coloração roxa, mas também se encontram pelitos vermelhos e brancos. Apresentam grande frequência por todos os perfis estudados.

Os perfis têm, em média, 10 m de espessura, mas podem atingir até $25 \mathrm{~m}$. Estão organizados em ciclos distintos de granodecrescência ascendente (finingupward cycles) que variam de 1 a $6 \mathrm{~m}$ de espessura. Alguns desses perfis encontram-se capeados por bauxitas e perfis lateríticos ferruginosos.

Na região de Óbidos foi possível dividir a Formação Alter do Chão em duas porções, uma inferior e outra superior. A porção inferior é formada por camadas tabulares de arenitos finos a médios com até $3 \mathrm{~m}$ de espessura, onde pequenas intercalações lenticulares de pelitos ocorrem e camadas tabulares de pelitos maciços e bioturbados com até $3 \mathrm{~m}$ de espessura. A porção superior é dominada por arenitos médios a grossos com geometria tabular que atingem até $20 \mathrm{~m}$ de espessura e podem conter intercalados pelitos maciços de pouca espessura. Na poção NW dos perfis não foi possível observar essa divisão, isso pode ser função de: corte e exposição dos barrancos, neotectônica e/ou não deposição nessa porção. Níveis de conglomerado são observados nessa porção.

A análise de fácies e estratigráfica, abordadas nesse trabalho, permitiu a proposição da carta litoestratigráfica (Fig. 4), para região de Óbidos, a qual demonstra variação e distribuição lateral das fácies da Formação Alter do Chão, nessa região.

\section{Conglomerado maciço - Cm}

Descrição: esta fácies é formada por clastos de argilito além de fragmentos de granitos e gnaisses. Os clastos, medindo 3 a $10 \mathrm{~cm}$ de comprimento, são subangulosos e subarredondados e pobremente selecionados (Fig. 5A). O conglomerado é geralmente suportado por matriz argilosa caulínica à areno-quartzosa, de granulometria média a grossa e mal selecionada. A maioria dos clastos apresenta disposição paralela ao acamamento, embora seixos imbricados também ocorram. As camadas mostram textura maciça e exibem contato inferior sempre erosivo e, superior geralmente gradacional.

Em muitos casos essa fácies é sobreposta por arenitos médios a grossos da fácies Aa e sotoposta por pelitos maciços da fácies $\mathrm{Pm}$, que representa a parte superior dos ciclos granodecrescentes ascendentes. A fácies $\mathrm{Cm}$ está presente na base dos ciclos sob forma de lag que alcança até $0,5 \mathrm{~m}$ de espessura, preenchendo superfícies basais erosivas côncavas.

Interpretação: a forma maciça das camadas e a má seleção dos clastos que são, em partes, imbricados sugerem uma sedimentação relativamente rápida com fluxo de alta energia. As características dessa fácies são consistentes com deposição em canais fluviais com alta velocidade de fluxo nas partes internas do canal sob forma de lag (Allen 1970, Miall 1992, Collinson 1996).

\section{Arenito com estratificação cruzada acanalada - Aa}

Descrição: essa fácies é formada por arenitos com grãos subangulosos a subarredondados, médios a grossos, moderados a pobremente selecionados arranjados em sets e cosets com estratificação cruzada acanalada, de médio a grande porte, cujos foresets apresentam segregação de grãos grossos de quartzo.

Essa fácies ocorre em sets únicos ou compostos, sendo que ambos têm padrão único de paleocorrente (Fig. 5C). A inclinação dos foresets varia de 8 a $16^{\circ}$ e geralmente em direção a sudoeste e oeste. Ocorrem, com certa frequência, seixos líticos arredondados-subarredondados de argilitos com até $2 \mathrm{~cm}$ de diâmetro, que estão expostos na base das fácies. Geometricamente, essa fácies ocorre como corpos lenticulares ou adelgaçados e comumente organizados em camadas com 
๗
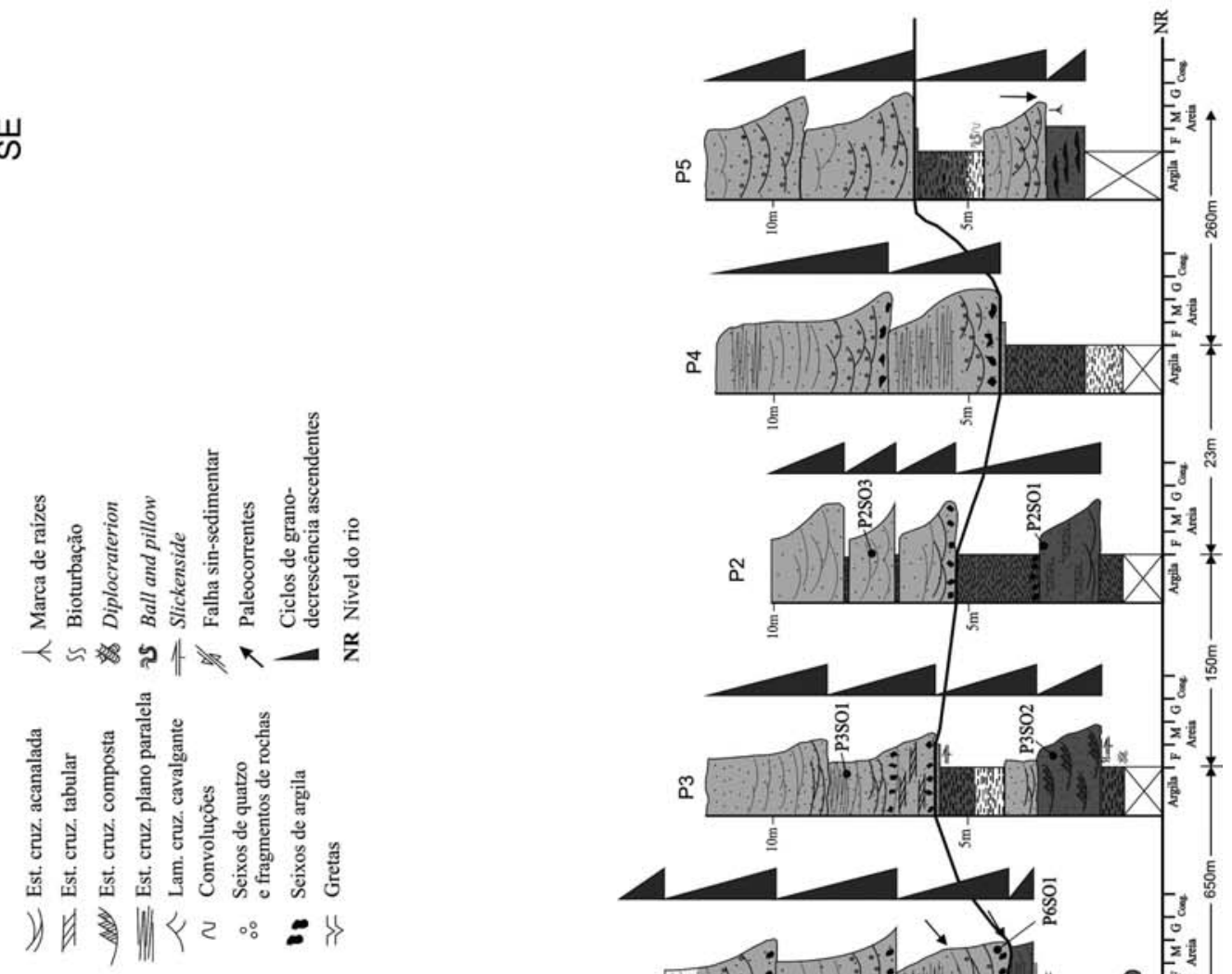

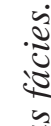

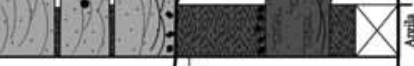

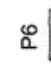
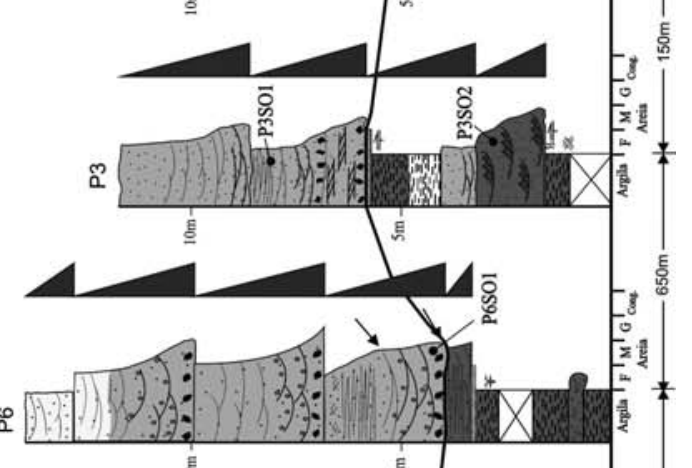

1
0
0
0
0
0

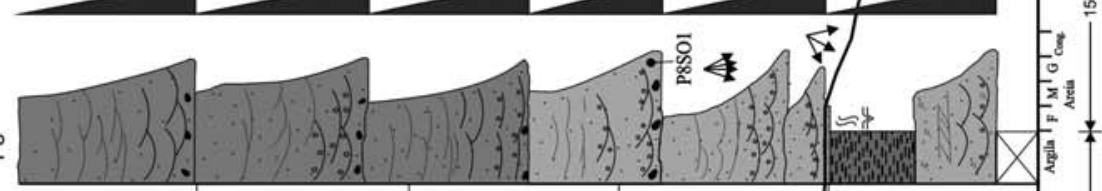

籾 总

\&

हूँ

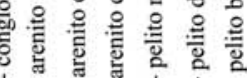

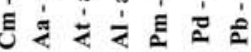

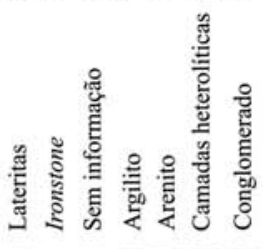

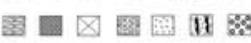
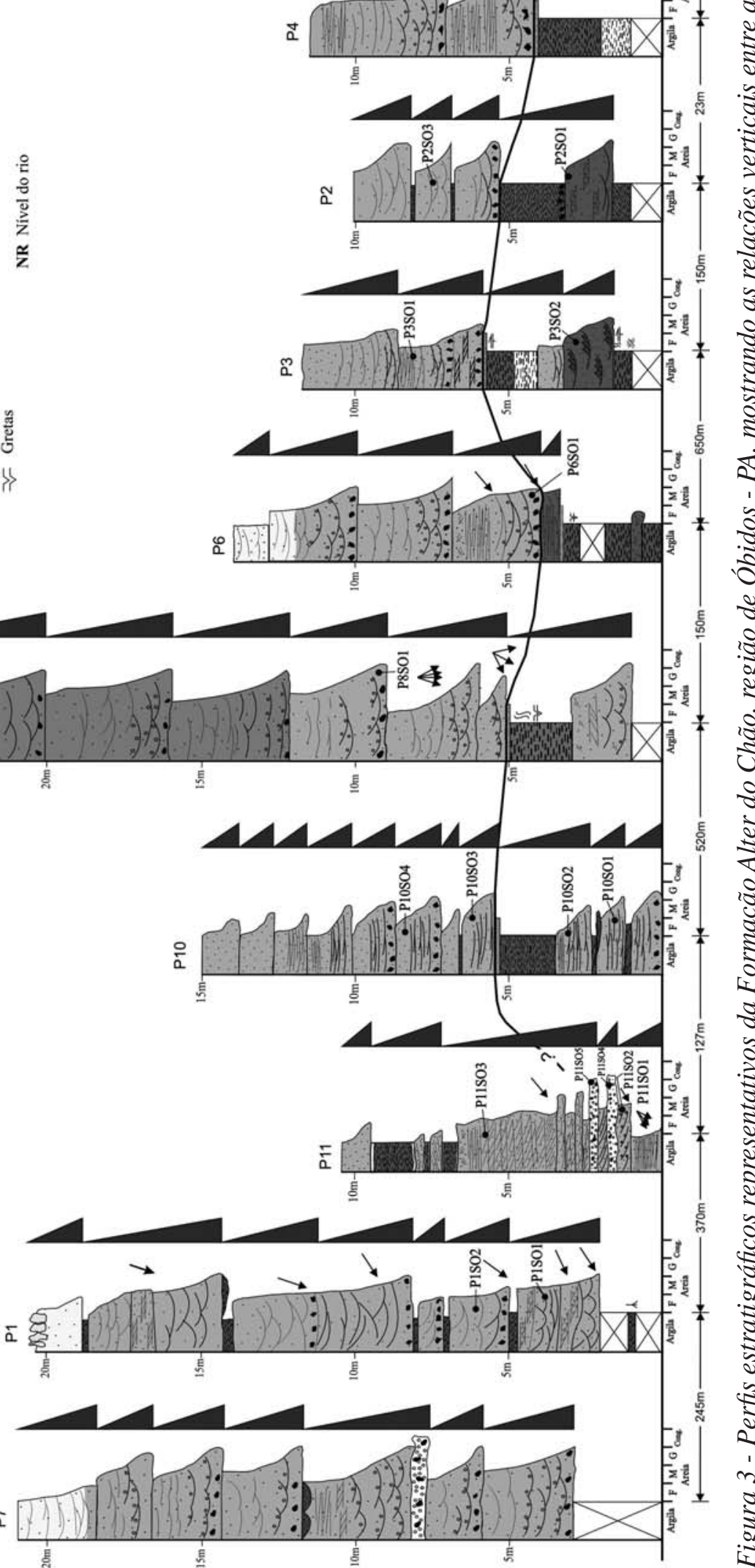
Tabela 1 - Sumário das feições características das litofácies identificadas da Formação Alter do Chão, na região de Óbidos - PA.

\begin{tabular}{|c|c|c|c|c|c|c|c|}
\hline Fácies & $\mathrm{Cm}$ & At & Aa & Al & Pm & $\mathbf{P b}$ & Pd \\
\hline Litologia & $\begin{array}{c}\text { Conglomerado } \\
\text { grosso a muito } \\
\text { grosso, com } \\
\text { clay balls e } \\
\text { raros clastos } \\
\text { de granitos e } \\
\text { gnaisses }\end{array}$ & $\begin{array}{l}\text { Arenito médio } \\
\text { a grosso, com } \\
\text { seixos de } \\
\text { argila e clastos } \\
\text { de granitos. } \\
\text { Seleção mode- } \\
\text { rada }\end{array}$ & $\begin{array}{l}\text { Arenito médio } \\
\text { a grosso, } \\
\text { caulínico, } \\
\text { com clastos } \\
\text { de granito, } \\
\text { gnaisses e pe- } \\
\text { litos. Seleção } \\
\text { moderada }\end{array}$ & $\begin{array}{c}\text { Arenito fino } \\
\text { a médio, no } \\
\text { geral, bem } \\
\text { selecionado }\end{array}$ & $\begin{array}{l}\text { Pelito maciço } \\
\text { com cores } \\
\text { variadas (ver- } \\
\text { melhos, roxos, } \\
\text { verdes) inter- } \\
\text { calado com a } \\
\text { fácies Al }\end{array}$ & $\begin{array}{c}\text { Pelito com } \\
\text { cores variadas }\end{array}$ & Pelito roxo \\
\hline $\begin{array}{c}\text { Estruturas } \\
\text { sedimentares }\end{array}$ & $\begin{array}{c}\text { Maciço a } \\
\text { fracamente } \\
\text { estratificado }\end{array}$ & $\begin{array}{l}\text { Estratifica- } \\
\text { ção cruzada } \\
\text { tabular com } \\
\text { espessura en- } \\
\text { tre } 0,3 \text { a } 2 \text { m }\end{array}$ & $\begin{array}{c}\text { Estratificação } \\
\text { cruzada acana- } \\
\text { lada de médio } \\
\text { e grande porte } \\
\text { com espessura } \\
\text { de até } 0,7 \mathrm{~m} \text {. }\end{array}$ & $\begin{array}{l}\text { Laminação } \\
\text { cruzada é do- } \\
\text { minante, com } \\
\text { esporádicas } \\
\text { ocorrências } \\
\text { de estratifica- } \\
\text { ções cruzadas } \\
\text { tabulares e } \\
\text { acanalada }\end{array}$ & $\begin{array}{l}\text { Maciço ou } \\
\text { fracamente } \\
\text { laminado, } \\
\text { nódulos ferru- } \\
\text { ginosos }\end{array}$ & $\begin{array}{c}\text { Bioturbação e } \\
\text { estruturas de } \\
\text { sobrecarga? }\end{array}$ & $\begin{array}{c}\text { Slickensides; } \\
\text { convoluções; } \\
\text { ball and } \\
\text { pillow }\end{array}$ \\
\hline
\end{tabular}

\begin{tabular}{|c|c|c|c|c|c|c|c|}
\hline $\begin{array}{c}\text { Feições inter- } \\
\text { nas }\end{array}$ & $\begin{array}{l}\text { Organizado } \\
\text { em cosets } \\
\text { exibindo } \\
\text { uniformidade } \\
\text { vertical ou } \\
\text { discreta grano- } \\
\text { decrescência } \\
\text { ascendente }\end{array}$ & $\begin{array}{l}\text { Granulome- } \\
\text { tria vertical } \\
\text { uniforme. } \\
\text { Foresets } \\
\text { coincidentes } \\
\text { com a fácies } \\
\text { Aa. Segrega- } \\
\text { ção de grãos } \\
\text { de quartzo nos } \\
\text { foresets }\end{array}$ & $\begin{array}{l}\text { Granulometria } \\
\text { uniforme com } \\
\text { segregação } \\
\text { de grãos de } \\
\text { quartzo nos } \\
\text { foresets. }\end{array}$ & $\begin{array}{l}\text { Laminações } \\
\text { internas }\end{array}$ & $\begin{array}{l}\text { Granulometria } \\
\text { uniforme nos } \\
\text { perfis. Feições } \\
\text { pedogenéticas } \\
\text { locais }\end{array}$ & & \\
\hline Contatos & $\begin{array}{l}\text { O limite infe- } \\
\text { rior é erosivo } \\
\text { com a fácies } \\
\text { Pm, o superior } \\
\text { é transicional } \\
\text { e plano com a } \\
\text { fácies At }\end{array}$ & $\begin{array}{c}\text { O limite infe- } \\
\text { rior é erosivo } \\
\text { e irregular } \\
\text { com as fácies } \\
\text { Cm e Aa e } \\
\text { superior adel- } \\
\text { gaçado com a } \\
\text { fácies Pm e/ } \\
\text { ou } \mathrm{Pb}\end{array}$ & $\begin{array}{c}\text { O contato } \\
\text { inferior é } \\
\text { erosivo com } \\
\text { a fácie At ou } \\
\text { com a fácies } \\
\text { Cm; e superior } \\
\text { transicional } \\
\text { com a fácies } \\
\text { At }\end{array}$ & $\begin{array}{c}\text { O limite infe- } \\
\text { rior é erosivo } \\
\text { com a fácies } \\
\text { At; e superior } \\
\text { é plano com } \\
\text { as fácies Pm } \\
\text { e Pd }\end{array}$ & $\begin{array}{l}\text { O limite infe- } \\
\text { rior é erosivo } \\
\text { com a fácies } \\
\text { Aa; e superior } \\
\text { plano com a } \\
\text { fácies Pd e Al }\end{array}$ & $\begin{array}{l}\text { Irregular com } \\
\text { fácies At e } \\
\text { plano com Pm }\end{array}$ & $\begin{array}{l}\text { Limite inferior } \\
\text { erosivo com } \\
\text { a fácies Aa, e } \\
\text { plano com a } \\
\text { fácies Pm }\end{array}$ \\
\hline Geometria & $\begin{array}{l}\text { Lenticular ou } \\
\text { tabular }\end{array}$ & $\begin{array}{l}\text { Lenticular ou } \\
\text { tabular }\end{array}$ & $\begin{array}{c}\text { Em forma de } \\
\text { cunha }\end{array}$ & $\begin{array}{c}\text { Pequenas } \\
\text { cunhas finas e } \\
\text { descontínuas }\end{array}$ & Tabular & Tabular & Tabular \\
\hline $\begin{array}{l}\text { Extensão } \\
\text { lateral }\end{array}$ & $\begin{array}{l}\text { Os corpos } \\
\text { arenosos se } \\
\text { estendem por } \\
\text { centenas de } \\
\text { metros }\end{array}$ & $\begin{array}{l}\text { Os corpos } \\
\text { arenosos se } \\
\text { estendem } \\
\text { entre dezenas } \\
\text { até centena de } \\
\text { metros }\end{array}$ & $\begin{array}{c}\text { Estendem-se } \\
\text { entre dezenas } \\
\text { até centena de } \\
\text { metros }\end{array}$ & $\begin{array}{l}\text { Corpos areno- } \\
\text { sos descon- } \\
\text { tínuos com } \\
\text { pinch-out de } \\
\text { até } 10 \mathrm{~m}\end{array}$ & $\begin{array}{c}\text { Observada e } \\
\text { traçada por até } \\
1.000 \mathrm{~m}\end{array}$ & $\begin{array}{l}\text { Desenvolvida } \\
\text { por até } 50 \mathrm{~m}\end{array}$ & $\begin{array}{c}\text { Moderada por } \\
\text { até } 200 \mathrm{~m}\end{array}$ \\
\hline Interpretação & $\begin{array}{l}\text { Depósitos re- } \\
\text { siduais (lags) }\end{array}$ & $\begin{array}{c}\text { Migração } \\
\text { de barras } \\
\text { ou dunas } \\
\text { com cristas } \\
\text { retas por fluxo } \\
\text { unidirecional } \\
\text { em regime de } \\
\text { fluxo inferior }\end{array}$ & $\begin{array}{l}\text { Migração } \\
\text { de dunas de } \\
\text { cristas sinuo- } \\
\text { sas por fluxo } \\
\text { unidirecional } \\
\text { em regime de } \\
\text { fluxo inferior }\end{array}$ & $\begin{array}{c}\text { Ripples } \\
\text { geradas em re- } \\
\text { gime de fluxo } \\
\text { inferior. Reco- } \\
\text { brem barras e } \\
\text { caracterizam } \\
\text { depósitos de } \\
\text { crevasse e } \\
\text { planície de } \\
\text { inundação }\end{array}$ & $\begin{array}{l}\text { Deposição } \\
\text { a partir de } \\
\text { suspensão em } \\
\text { área externa } \\
\text { ao canal e, } \\
\text { localmente, } \\
\text { alteração por } \\
\text { processos pe- } \\
\text { dogenéticos }\end{array}$ & $\begin{array}{l}\text { Deposição } \\
\text { a partir de } \\
\text { suspensão em } \\
\text { área externa } \\
\text { ao canal e } \\
\text { perda de es- } \\
\text { trutura gerada } \\
\text { por atividade } \\
\text { biogênica }\end{array}$ & $\begin{array}{c}\text { Deposição } \\
\text { a partir de } \\
\text { suspensão e } \\
\text { processos de } \\
\text { sobrecarga e/ } \\
\text { ou atividade } \\
\text { tectônica }\end{array}$ \\
\hline
\end{tabular}




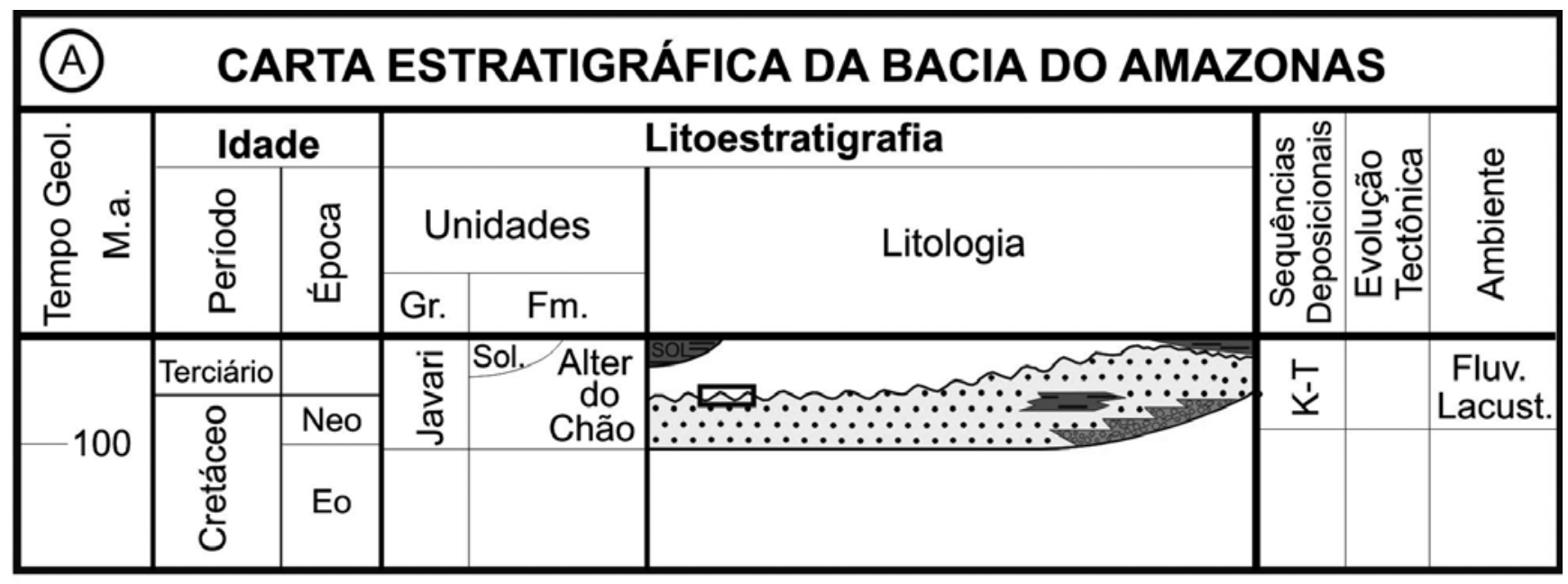

\begin{tabular}{|c|c|c|c|c|}
\hline Idade & $\mathrm{Fm}$. & Litologia & Descrição & Amb. \\
\hline \multirow{2}{*}{ 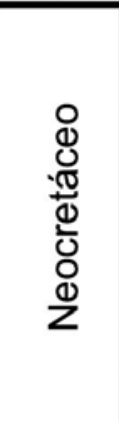 } & \multirow{2}{*}{ 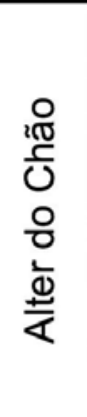 } & $\because \because \because$ SE & $\begin{array}{l}\text { Conglomerados com seixos de quartzo. Contatos } \\
\text { inferior e superior são erosivos com arenitos médios } \\
\text { e finos com estratificação cruzada acanalada e tabular. } \\
\text { Pelitos vermelhos maciços com pouca expressão. } \\
\text { Podem pree n cher peque nas depres so es es } \\
\text { (paleocanais?). Predomínio das fácies areníticas } \\
\text { frente a conglomerados e pelitos. }\end{array}$ & \multirow{2}{*}{ 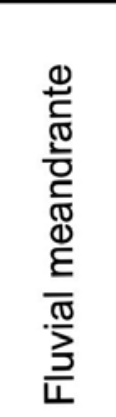 } \\
\hline & & ---- & $\begin{array}{l}\text { Arenitos médios e grossos, mal selecionados e com } \\
\text { estratificação cruzada acanalada e tabular. Pelitos } \\
\text { roxos e vermelhos maciços, bioturbados e } \\
\text { deformados. Predomínio das fácies pelíticas frente a } \\
\text { conglomerados earenitos. }\end{array}$ & \\
\hline
\end{tabular}

Figura 4 - Carta estratigráfica da bacia do Amazonas. Modificada de Eiras (1998); B) Carta litoestratigráfica proposta para Formação Alter do Chão na região de Óbidos - PA.

estratificação cruzada acanalada com extensão lateral por varias dezenas de metros. O limite inferior é erosivo com a fácies $\mathrm{Cm}$, enquanto o contato superior é gradacional e irregular com os arenitos da fácies At.

Interpretação: a seleção moderada a pobre dos arenitos, sua geometria lenticular e a predominância de orientação unimodal dos sentidos dos estratos cruzados favorecem uma interpretação de formas de leito fluviais (Collinson 1996, Miall 1996). A suave inclinação dos foresets e a granulometria grosseira sugerem que grandes sets dessa fácies provavelmente se formaram em frentes de barras com baixo ângulo de inclinação (Smith 1970), enquanto estratificações menores foram geradas por dunas ou megaripples que migraram sobre ou cruzando as margens dessas barras (Collinson 1996), como indicado pela presença de cosets compostos de estratos cruzados, com a inclinação das superfícies dos cosets representando a frente da barra.

A ausência de plantas fósseis e detritos vegetais (marcas e/ou fragmentos) provavelmente refletem a prevalência de condições climáticas semiáridas que não favorecem preservação de restos vegetais. A extensão lateral considerável da fácies Aa, sua relação com outras fácies e o espalhamento no sentido de mergulho dos estratos cruzados (Fig. 7) sugerem que essas fácies foram depositadas em uma ampla e levemente inclinada planície de rio.

\section{Arenito com estratificação cruzada tabular - At}

Descrição: essa fácies consiste em arenitos finos a grossos, mal selecionados com estratificação cruzada tabular, cujos sets atingem até $2 \mathrm{~m}$ de espessura. Ocorre ainda internamente, estratificação plano-paralela (Fig. 5B) e segregação de seixos de quartzo nos foresets. O acamamento planar da fácies At apresenta baixo ângulo (5 a $15^{\circ}$ ). A espessura dos foresets diminui em direção ao topo das seções juntamente com a granulometria e a orientação dos foresets nos estratos cruzados indica paleofluxo unidirecional para SE (Fig. 8, P4). O contato inferior dessa fácies é gradacional e plano, enquanto o superior é tipicamente erosivo, podendo ser localmente ondulado, com as fácies $\mathrm{Al}$ e Pm. 

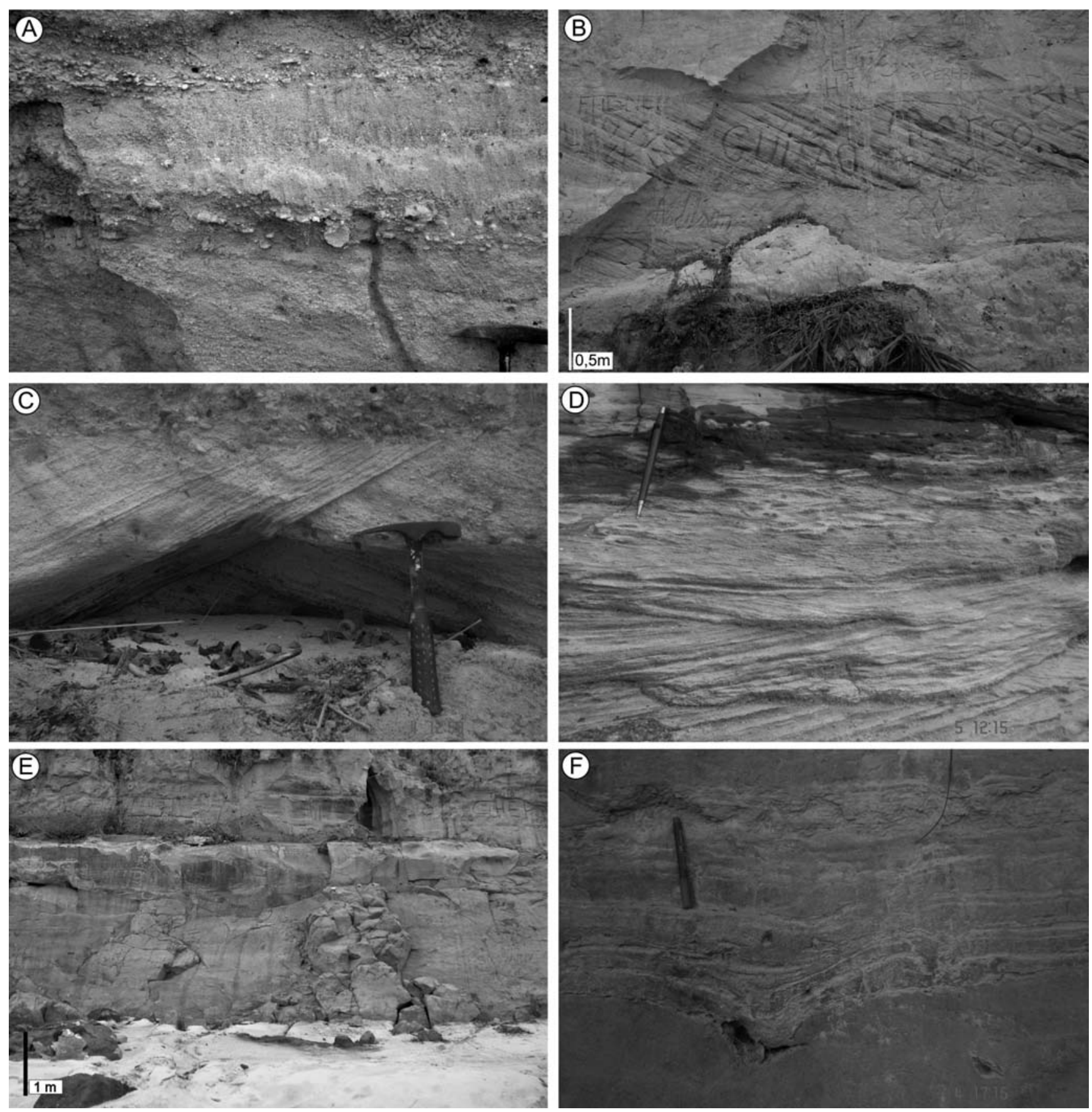

Figura 5 - Litofácies identificadas da Formação Alter do Chão, Óbidos - PA. A) conglomerado maciço e seixos de argila, fácies $\mathrm{Cm}$; B) arenito com estratificação cruzada tabular, fácies At; C) arenito com estratificação cruzada acanalada, fácies Aa. Notar contato com a fácies $\mathrm{Cm}$ na parte superior da foto; D) arenito com laminação cruzada, fácies Al; E) Pelito maciço, fácies Pm e; F) Pelito deformado, fácies Pd.

Interpretação: a fácies At é interpretada como sendo formada por migração de barras com cristas retas (Collinson 1996, Miall 1996) depositadas em regime de fluxo inferior. A formação de estratificação cruzada de baixo ângulo dentro dos sets de maior escala da fácies At indica que esses sets foram produtos de migração de barras (Cant \& Walker 1976, Sharma et al. 2002). Ao contrário, a inclinação mais íngreme da estratificação cruzada tabular é característica de sets em pequena escala, sendo considerados produtos de migração de dunas 2-D com cristas retas (Ashley 1990), possivelmente, associado com barras fluviais (Collinson 1996).

$\mathrm{O}$ contato superior da fácies At com a fácies $\mathrm{Al}$ e o estilo lateralmente adelgaçado da barra indicam que sua altura pode ter sofrido progressiva redução, possivelmente em direção aos bancos do rio (Mazumder 
\& Sarkar 2004). Em alguns casos, pequenos cortes (scours) ocorrem no topo das barras (Walker 1978) e, embora muitos desses cortes tenham sido preenchidos com areia, logo após a formação, alguns foram preenchidos com argila durante períodos de menor energia.

A divergência de orientação das paleocorrentes entre as fácies At e Aa, é provavelmente um reflexo da deposição primária na frente ou na parte oblíqua das barras do canal principal e barras transversais de canais secundários onde as fácies de avalanche das camadas estão oblíquas a orientação predominante do canal (Cant \& Walker 1978).

\section{Arenito com laminação cruzada cavalgante - Al}

Descrição: essa fácies (Fig. 5D) usualmente ocorre associada às fácies de pelitos e consiste em arenito fino que, no geral, é bem selecionado. Possui geometria em forma de cunha que, lateralmente ocorre por poucos metros e contêm abundantes marcas assimétricas, laminação plano-paralela, sets cruzados em pequena escala e estratificação cruzada planar. O sentido de mergulho das lâminas cruzadas é o mesmo da fácies Aa. Essa fácies atinge poucas espessuras $(<0,5 \mathrm{~m})$ e grada lateral e verticalmente a sedimentos mais finos das fácies Pm e Pd.

Interpretação: a presença de marcas assimétricas e estratificação cruzada cavalgante recoberta por argila indica deposição tanto por suspensão como por tração (Miall 1996). Essa fácies provavelmente representa o abandono temporário da migração das barras e/ ou produto de deposição, entre as barras, ou em áreas de planícies de inundação (Bose \& Chakraborty 1994, Collinson 1996).

\section{Pelito maciço - Pm}

Descrição: essa fácies é frequente em todos os perfis sendo formada por pelitos de cores variadas (Fig. 5E) (vermelhos, roxos, verdes escuros), que podem ocorrer intercalados com a fácies $\mathrm{Al}$. A fáceis $\mathrm{Pm}$ é maciça com contato inferior gradacional, enquanto o superior é erosivo com a fácies Aa. As camadas de pelito variam entre 0,3 a $2 \mathrm{~m}$ de espessura e apresentam geometria tabular.

Interpretação: a fácies Pm representa deposição a partir de suspensão em planícies inundadas onde os sedimentos finos recobrem os demais depósitos. Finas camadas de arenitos são comumente associadas com os pelitos e representam depósitos de espraiamento de crevasse adjacentes ao canal principal do rio. Exposições subaéreas dos pelitos são indicadas pela presença de gretas de dissecação. Pelitos vermelhos e roxos, associados com gretas de dissecação, são provavelmente, o resultado de intemperismo atual ou subatual, embora a interpretação como red beds desenvolvidos em condições semiáridas não possa ser descartada (Van Houten 1973, Turner 1980, Bridge 2006, Cain \& Mountney 2009).

\section{Pelito deformado - Pd}

Descrição: esta fácies (Fig. 5F) assim como fácies Pm é frequente. Formada por pelito deformado de cor avermelhada e geometria tabular, atinge até $0,7 \mathrm{~m}$ de espessura. As deformações são suaves com formas côncavas para baixo. Marcas de raízes ocorrem disseminadas. O contato superior do pelito é gradacional com a fácies Pm.

Interpretação: a fácies Pd é interpretada como deposição a partir de suspensão em planícies inundadas. Sobrecarga e/ou atividade tectônica, indicadas por slickensides, causaram a perda da estrutura primária bem como exposições subaéreas registradas por gretas de dissecação.

\section{Pelito bioturbado - Pb}

Descrição: a fácies $\mathrm{Pb}$, se comparada às demais fácies de pelitos (Pm e Pd) é menos representativa. É formada por pelito com bioturbação (icnofósseis e marcas de raízes), com espessura variando entre 0,2 e $1 \mathrm{~m}$, onde gretas de dissecação são frequentes.

Interpretação: a fácies $\mathrm{Pb}$ foi depositada em ambiente de planície de inundação. Sua pouca espessura e representatividade poderiam estar ligadas à limitada área de vegetação ou ao grau de atividade restrita biogênica.

ASSOCIAÇÃO DE FÁCIES As litofácies foram organizadas em duas associações (preenchimento de canal e depósitos externos ao canal), as quais agrupam subambientes característicos das mesmas (Tab. 2). Os depósitos de preenchimento de canal são constituídos de: barra conglomerática, macroformas arenosas e barras de acreção lateral enquanto os depósitos externos ao canal incluem dique marginal, espraiamento de crevasse e planície de inundação.

\section{Preenchimento de canal}

ASPECTOS GERAIS O canal é caracterizado por base erosiva que corta os depósitos de planície de inundação (Fig. 6). Sua base tem forma irregular à côncava com até $2 \mathrm{~m}$ de profundidade. Os elementos que preenchem o canal compreendem barras conglomeradas sob forma de conglomerados maciços a fracamente estratificados (Cm), formas de leitos arenosas constituídos de arenitos grossos das fácies Aa e At e barras de acreção lateral. O contato erosivo entre pelitos (subjacente) e a fácies Cm é uma superfície de $5^{a}$ ordem (Miall 1985) que marca o início de cada ciclo granodecrescente ascendente nas sucessões. 


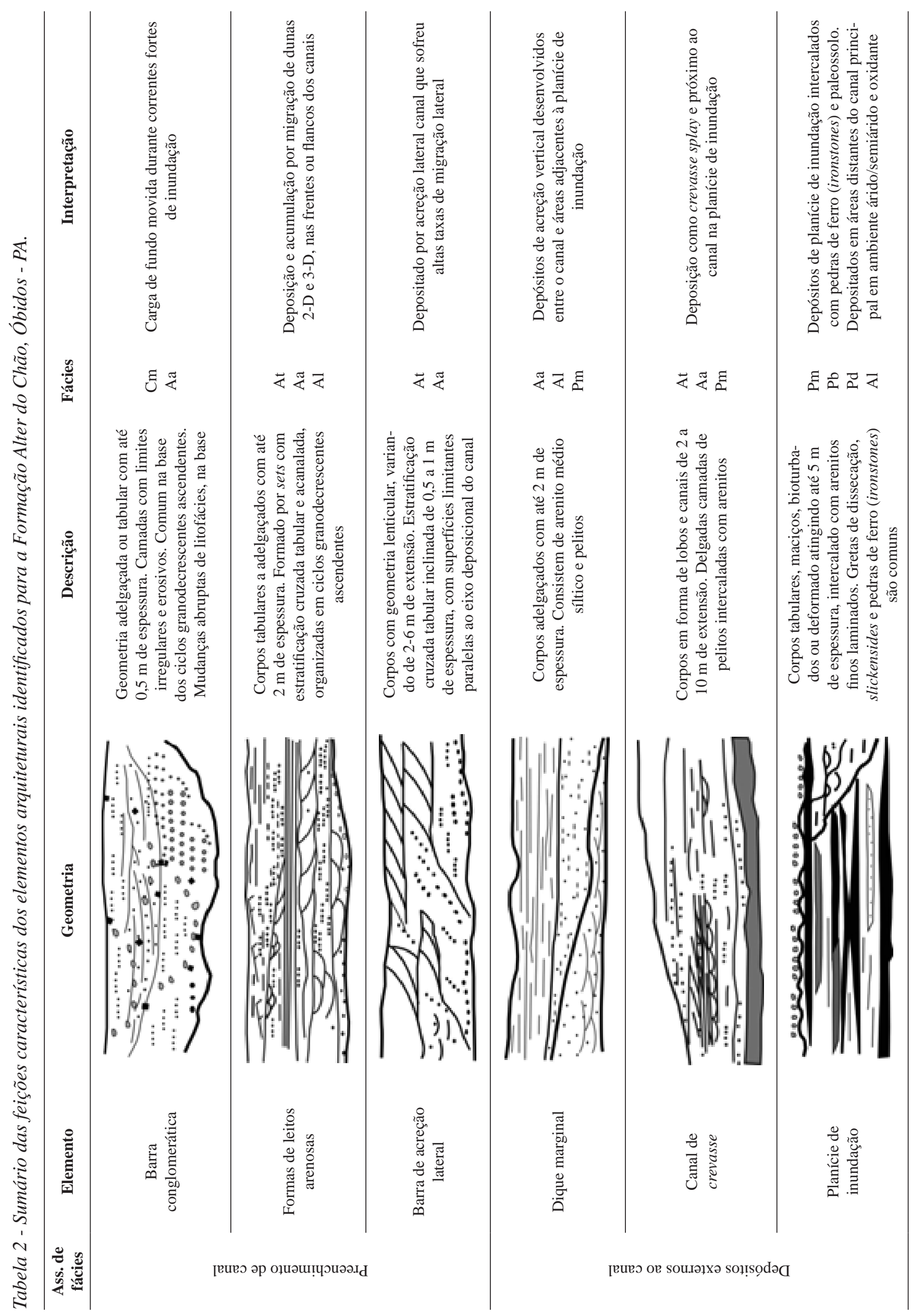



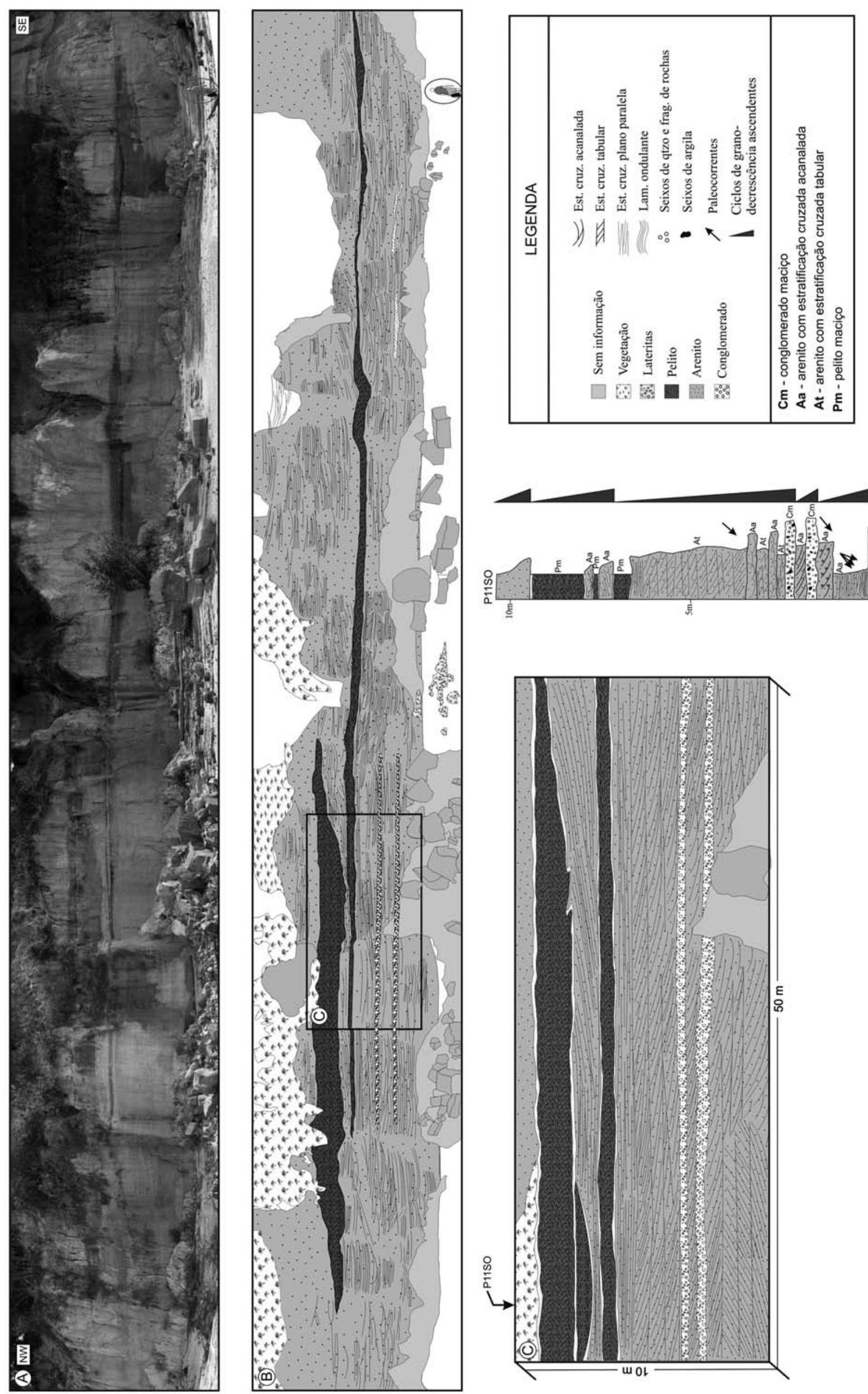

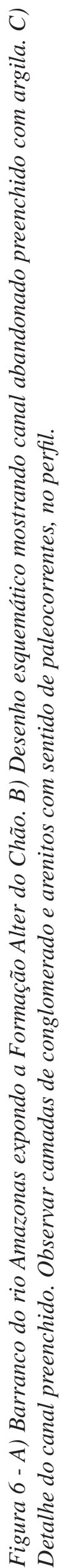


Nos perfis de Óbidos foram reconhecidos até onze ciclos de granodecrescência ascendente, que variam cada um de 1-6 m de espessura. Os canais podem ser traçados lateralmente por dezenas de metros. Sua margem, quando exposta, mostra geometria acunhada indicando pequenas incisões. Nestas margens, as fácies $\mathrm{Cm}$ e Aa apresentam-se com geometria em pinch-out.

BARRA CONGLOMERÁTICA Esse elemento é formado pelas fácies $\mathrm{Cm}$ e Aa. Possuem geometria lenticular traçáveis, lateralmente, por vários metros. Internamente, exibem mudanças, verticais e laterais, entre as fácies Cm e Aa, sendo que formam depósitos de lag, caracterizados por superfícies de baixo relevo e limites erosivos. A geometria lenticular a acunhada e finas camadas de Cm e Aa associados com superfícies escavadas indicam deposição de lag (Allen 1970, Leeder 1973).

\section{FORMAS DE LEITOS ARENOSAS Essas formas são} os elementos mais comuns e registrados em todas as seções estratigráficas dos arenitos de Formação Alter do Chão (Fig. 7). Apresentam geometria lenticular, tabular ou acunhada com espessura entre 1 e 5 m e extensão lateral por até $150 \mathrm{~m}$. Eles são compostos de camadas organizadas em ciclos de granodecrescência ascendentes, caracterizados por passagem de areias seixosas (Cm) as quais, seção acima, passam gradualmente a arenitos grossos com estratificação cruzada acanalada (Aa) ou arenitos médios a grossos com estratificação cruzada tabular (At), os quais são recobertos por sedimentos finos (Pm, Pd, $\mathrm{Pb}$ e Al) da planície de inundação. Os arenitos tabulares predominam nas partes médias dos ciclos de granodecrescência. A base dos leitos arenosos é composta de arenitos ricos em clastos de argila, que são produto de retrabalhamento dos pelitos da planície de inundação (fenômeno conhecido como 'terra caída'). A espessura das camadas das fácies Aa e At diminuem para o topo dos ciclos granodecrescentes.

A orientação dessas macroformas é geralmente normal à direção de paleofluxo, como mensurado nos foresets das fácies Aa e At. Dados de paleocorrente mostram uma dispersão moderada e um trend unimodal para sul-sudoeste (Figs. 7 e 8). A diminuição da espessura dos sets cruzados comumente indica mudanças nas formas de leito, de dunas para marcas onduladas, que refletem um decréscimo na energia de transporte do canal (Halfar et al. 1998).

BARRA DE ACREÇÃO LATERAL Esse elemento possui forma lenticular com $3 \mathrm{~m}$ de espessura e 10-15 m de extensão dominados por arenitos finos a médios sobrepostos a arenitos intercalados com pelitos (Fig. 8). Os sets com estratificação cruzada tabular são mais abundantes que os com estratificação cruzada acanalada. As superfícies inclinadas dos estratos tabulares são oblíquas ao sentido do canal indicado pelo sentido do mergulho da fácies Aa.

A interpretação como barra de acreção lateral ou em pontal é baseada no tamanho da barra, sua extensão lateral bem como no sentido das paleocorrentes (90-110 Az) oblíquos ao canal principal (Fig. 8-P4). As ocorrências de arenito com laminações parasíticas juntamente com ocorrência lateral desenvolvida também suportam a hipótese de uma barra em pontal. Medidas de paleocorrentes realizadas nos estratos das laminações parasíticas indicam sentido para $320-330^{\circ} \mathrm{Az}$ (Fig. 8-P1). A presença de mud plugs sobre arenitos da barra em pontal indica abandono abrupto ou por avulsão cut - off do canal.

\section{Depósitos externos ao canal}

DIQUE MARGINAL Este elemento apresenta formas tabulares com bordas delgadas que se estendem por algumas dezenas de metros e atingem até $2 \mathrm{~m}$ de espessura (Fig. 9). São formados por arenitos sílticos que gradam para arenitos finos, sendo estes sobrepostos por pelitos. A borda desse elemento ocorre em associação com a planície de inundação, sendo que esta recobre os depósitos do dique.

O reconhecimento como dique marginal foi baseado na relação com a margem do canal, interpretado como canal de crevasse (Fig. 9) e com a planície de inundação sugerindo interpretar este elemento como depósitos de diques marginais (Brierley et al. 1997). Os arenitos sílticos e finos são interpretados como depósitos que romperam os diques marginais (canal de crevasse) sobre a planície de inundação (Aslan \& Blum 1999).

CANAL DE CREVASSE Este elemento consiste em lóbulos a canais, com arenitos de granulometria média, na base, e fina, para o topo (Fig. 9), que formam corpos côncavos de $3 \mathrm{~m}$ de espessura por até $10 \mathrm{~m}$ de largura. Internamente, este elemento, apresenta estratificações cruzadas acanalada, tabular e plano-paralela. Além de pequenas marcas de raízes, gretas de dissecação e feições de bioturbação que ocorrem na parte superior desse elemento.

As camadas de pelito, cortadas por esse elemento, representam depósitos da planície de inundação. Com base no adelgaçamento lateral, redução granulométrica e relacionamento lateral com pelitos da planície de inundação, este elemento é interpretado como canal de crevasse (Capuzzo \& Wetzel 2004) que rompeu durante as cheias o dique marginal do canal.

PLANÍCIE DE INUNDAÇÃO A parte superior dos ciclos da Formação Alter do Chão é caracterizada por 

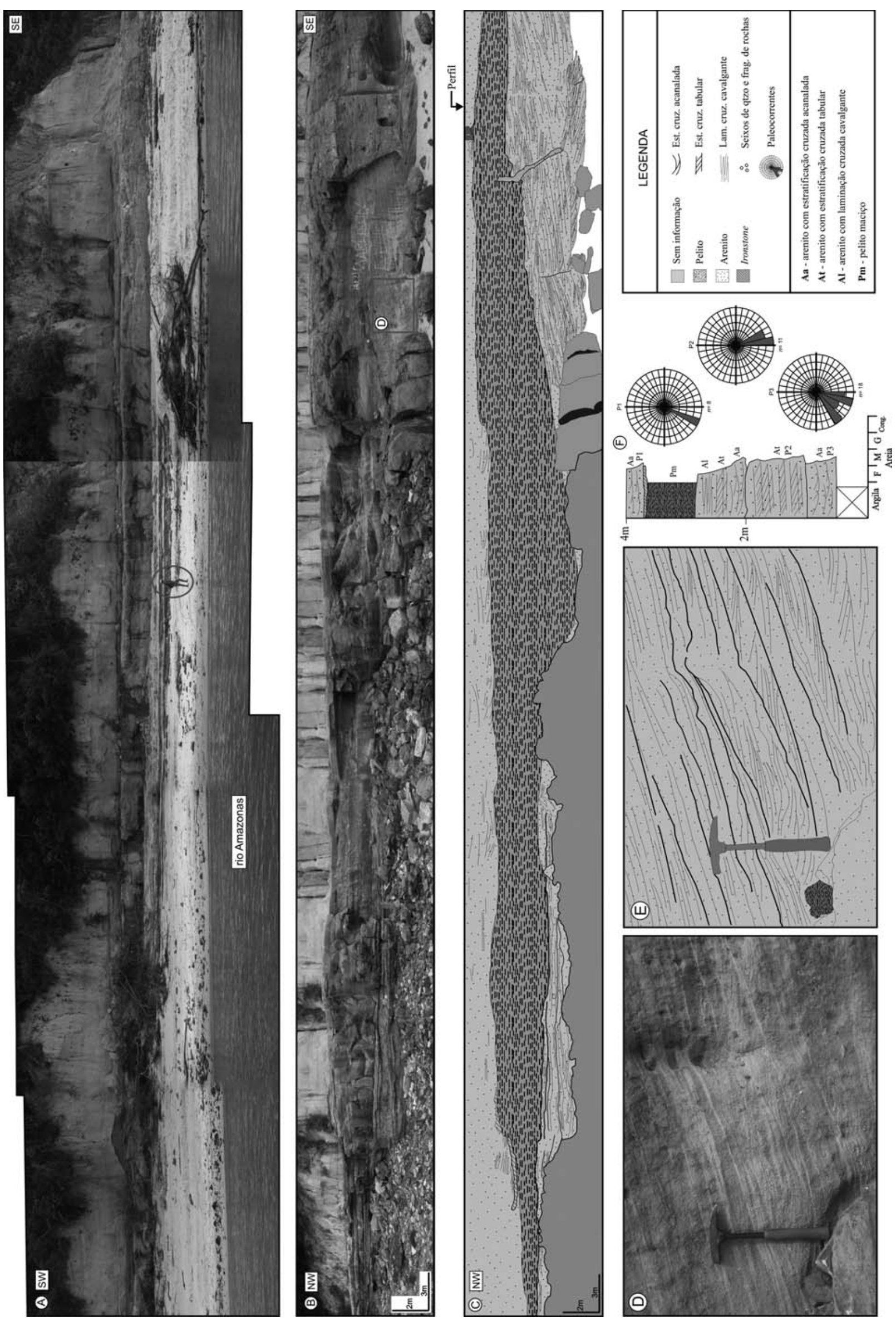

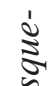

ֻ
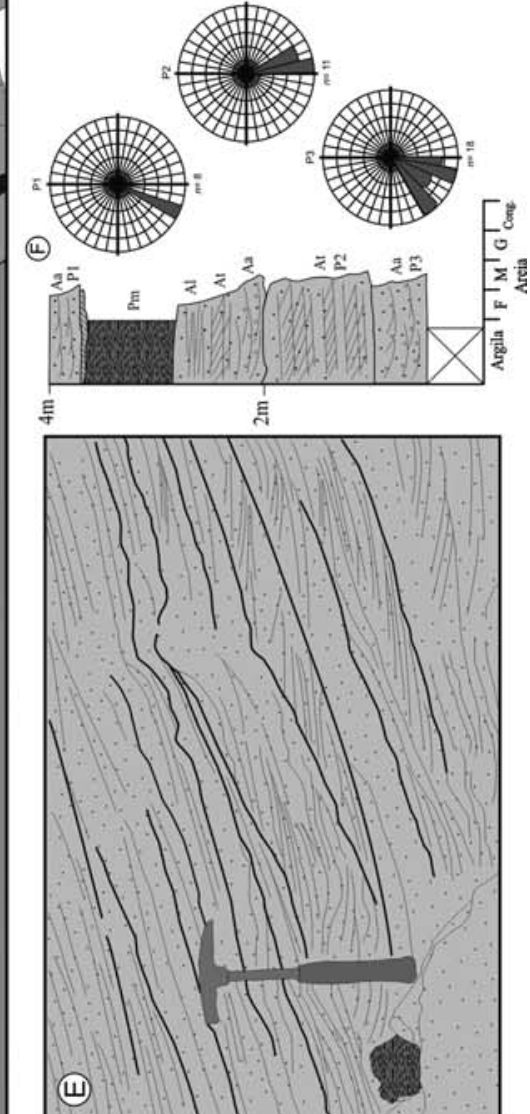

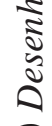

$\ddot{0}$

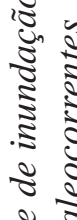

$\because \frac{0}{8}$

ㅎำ

눈

อ ह

ปิ

气

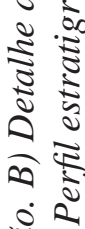

20

을

ఏ

จ

$\because$

은

:

กิ

:

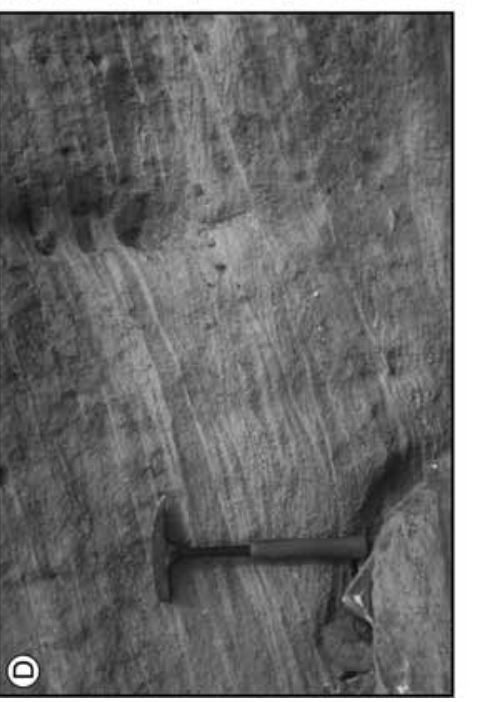

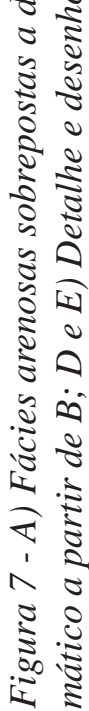



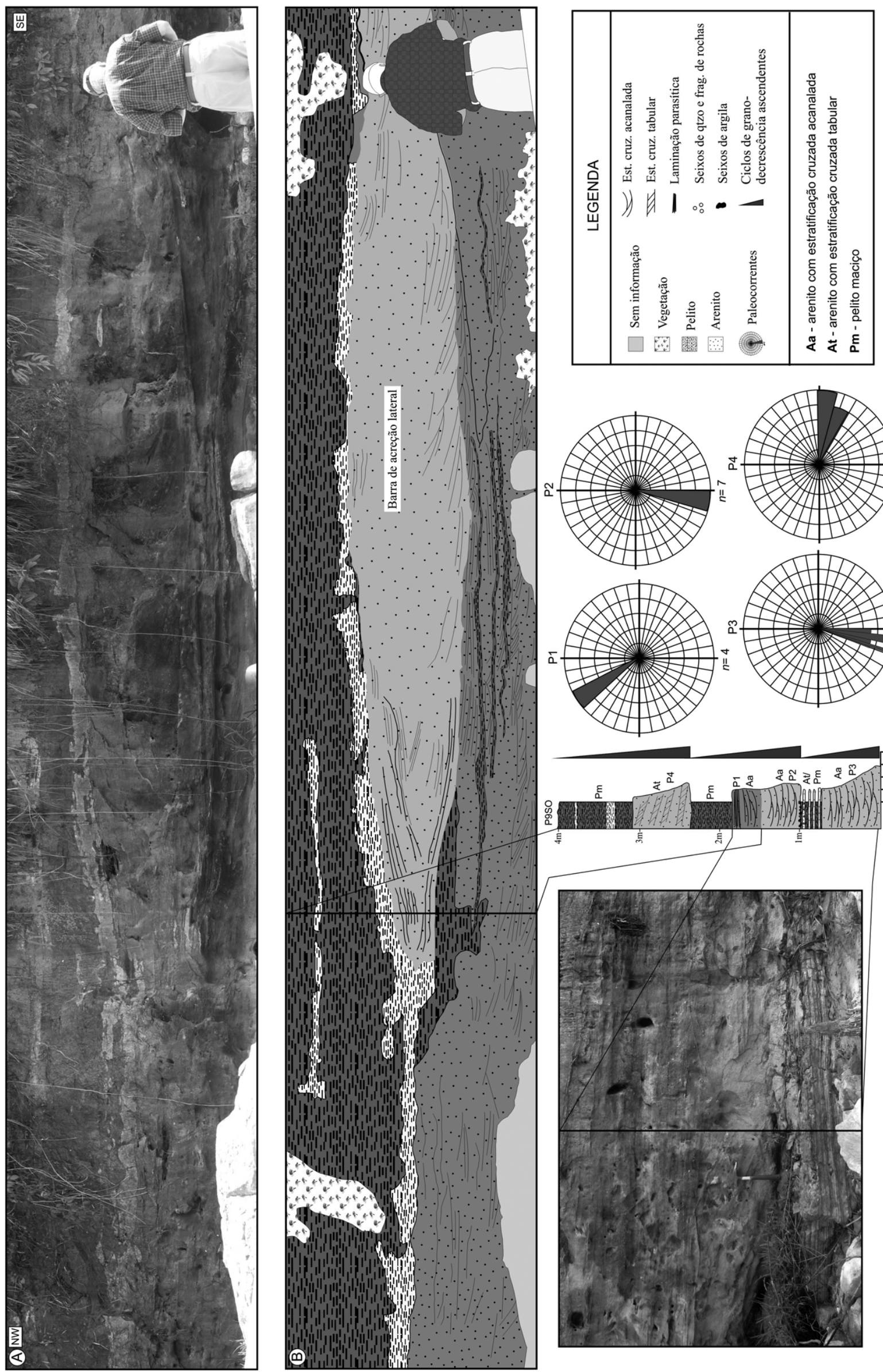

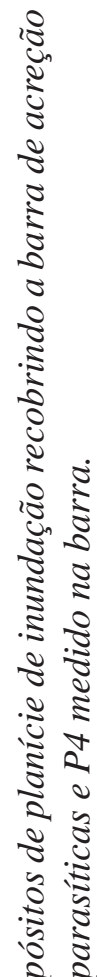
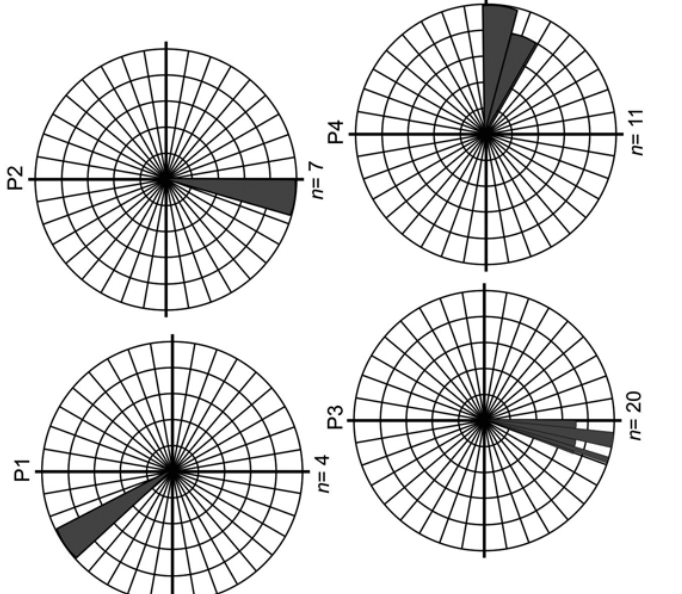

$\frac{1}{2}$

ઈิ نิ

ปे.

กิ ธ

ธิ हิ

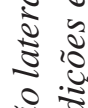

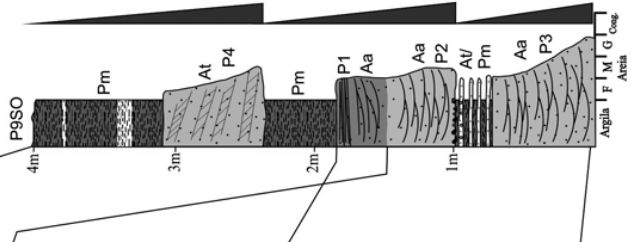

క్ల

ธิ

ป ธิ

ㅎำ 온

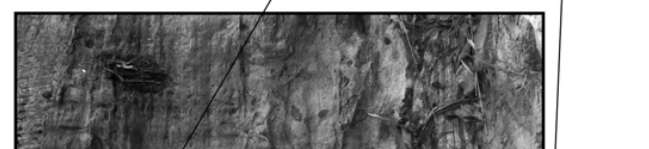

क :

ఏ.

0

:

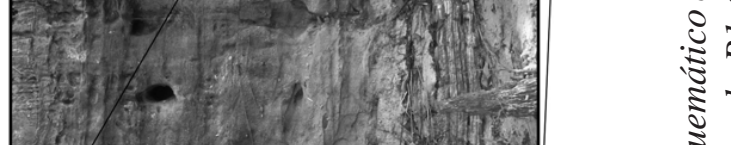

$\frac{2}{2} \frac{0}{2}$

ข

ฏ

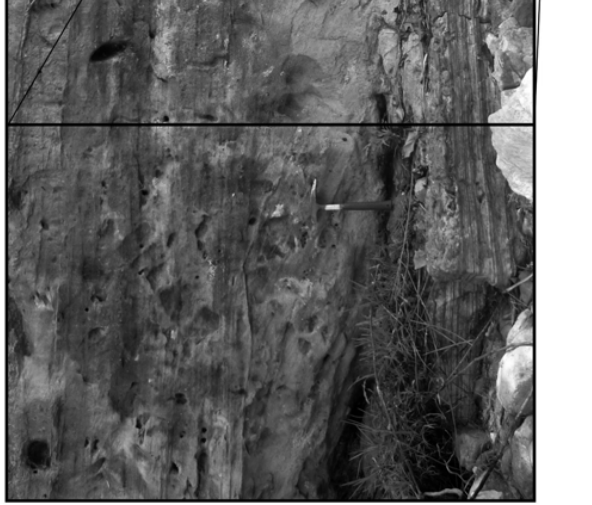

气ั้

กิ $\frac{8}{8}$

원

$\div 0$

压霌

$\infty$

$\infty$
$\vdots$
$\vdots$
$\vdots$
$\vdots$
0 

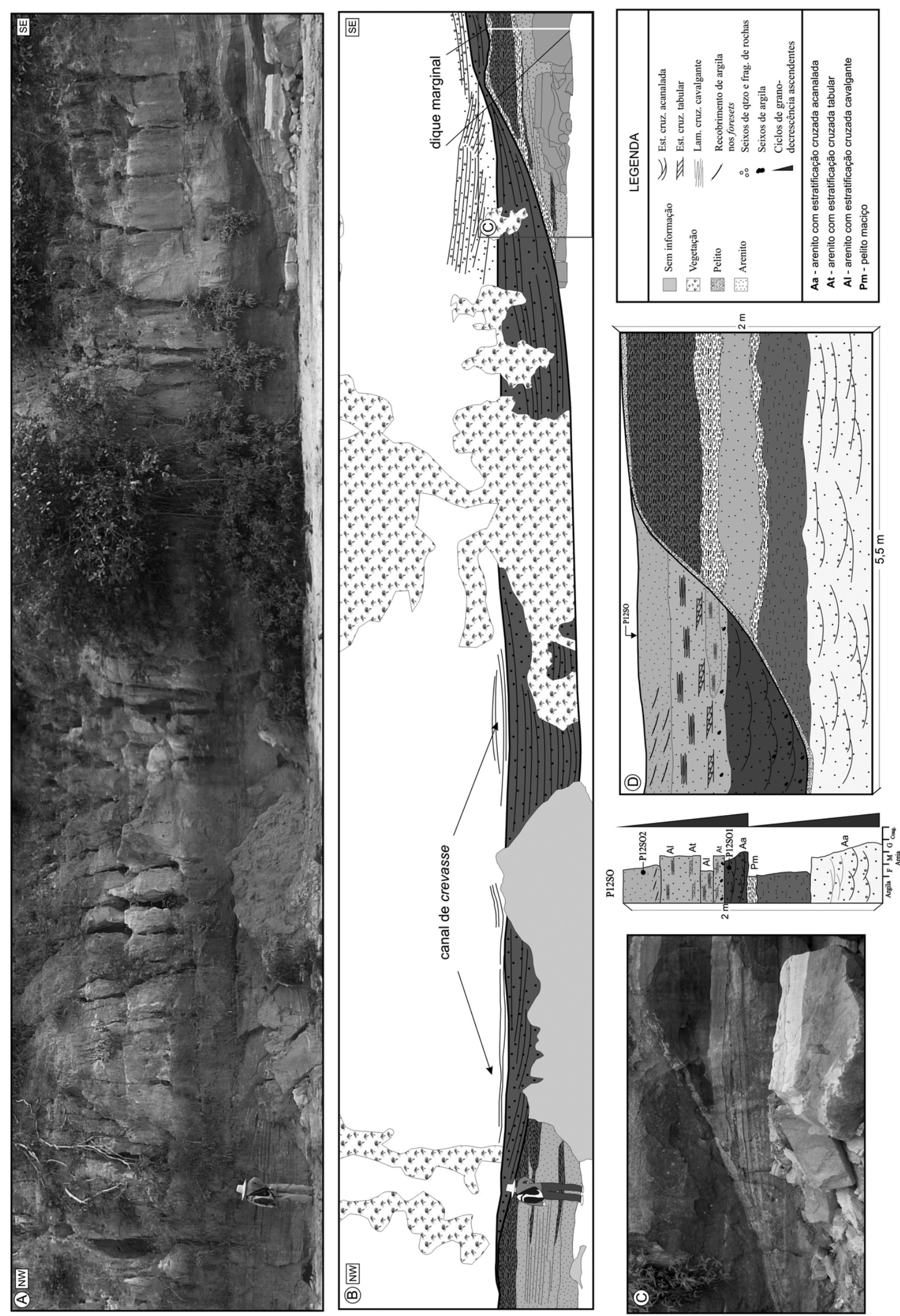

$\overline{5}$
ป
0
0
0
$\frac{0}{0}$
0
0
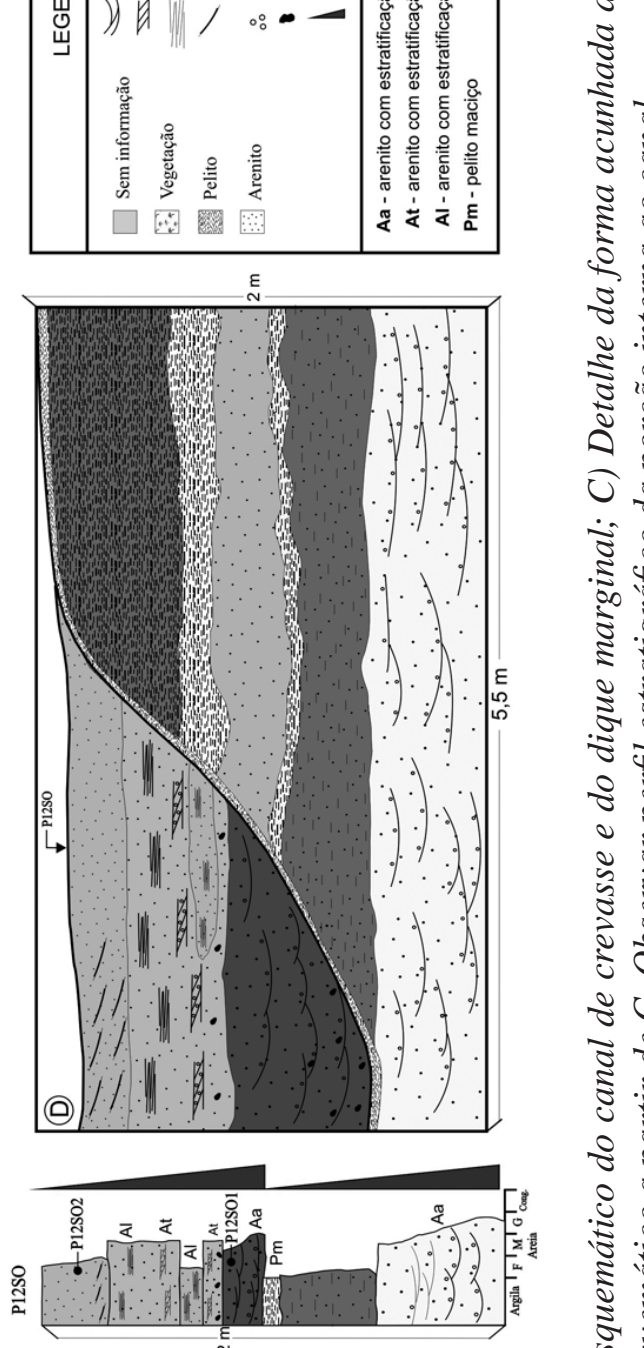

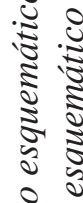

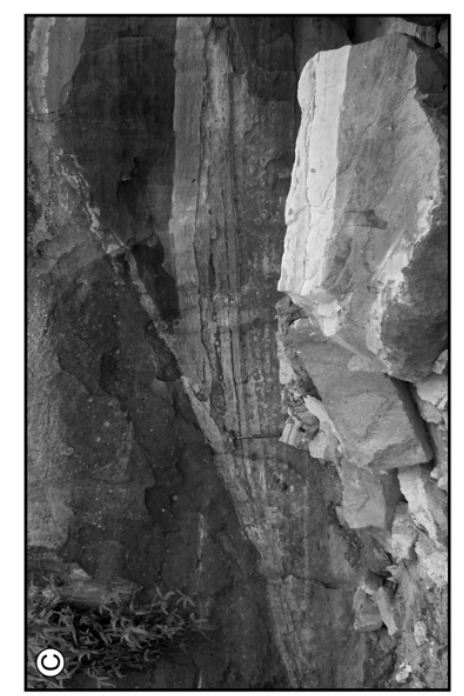

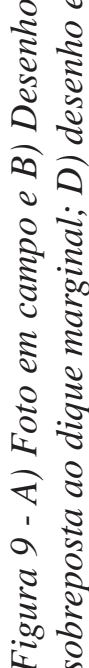


sucessões de até $3 \mathrm{~m}$ de espessura de pelitos roxos, avermelhados e amarelos interacamadados com arenitos finos da fácies Al (Fig. 7). Esses depósitos, de geometria tabular, podem ser traçados lateralmente por distâncias de até $300 \mathrm{~m}$ em direções paralelas e perpendicular aos canais. Partes dos argilitos com gretas de dissecação e dos arenitos finos são sotopostos por camadas de até $0,2 \mathrm{~m}$ de espessura de 'pedras de ferro' (ironstones). Essas 'pedras de ferro' (ironstones) indicam mobilização de $\mathrm{Fe}^{3+}$ e $\mathrm{Fe}^{2+}$ que sugerem frequentes flutuações no nível freático (Turner 1993). Podem ocorrer também feições pedogenéticas que incluem envelopes de argila e oxi-hidróxido de ferro nos grãos de quartzo, estruturas blocky (peds), marcas de raízes, bioturbação e slickensides (Retallack 1988, Kraus \& Aslan 1999).

Os elementos reconhecidos sugerem depósitos argilosos de planície de inundação com finos depósitos arenosos e paleossolo incipiente. A presença de múltiplos horizontes de paleossolos sugere tempo suficiente entre as inundações periódicas para o desenvolvimento de feições pedogenéticas, pelo menos, incipientes.
MODELO DEPOSICIONAL Os perfis da Formação Alter do Chão, na área em estudo, são contínuos lateralmente, por mais de $3,5 \mathrm{~km}$. São constituídos, principalmente de arenitos e, secundariamente, pelitos e conglomerados. As litofácies estão organizadas em ciclos de granodecrescência ascendente com predomínio das fácies Aa e At, atribuídas à migração de formas de leito com cristas sinuosas e retas, respectivamente, e à acreção lateral de arenitos, além de conglomerados da fácies $\mathrm{Cm}$, representando depósitos de lag no fundo dos canais. Os pelitos das fácies $\mathrm{Pm}, \mathrm{Pd}$ e $\mathrm{Pb}$, em partes intercaladas com arenitos finos a médios, na porção superior dos ciclos, são depósitos externos ao canal (overbank fácies).

Essas características aliadas à distribuição unimodal e mudança no sentido dos padrões de paleocorrente apontam para a Formação Alter do Chão, próximo a Óbidos, um sistema fluvial meandrante com variação em sinuosidade do canal e/ou carga de fundo. As fácies pelíticas são mais abundantes e espessas na parte inferior dos perfis, que nas partes superiores, sugerindo um sistema meandrante dominado por carga mista (mixed-load; Fig. 10).

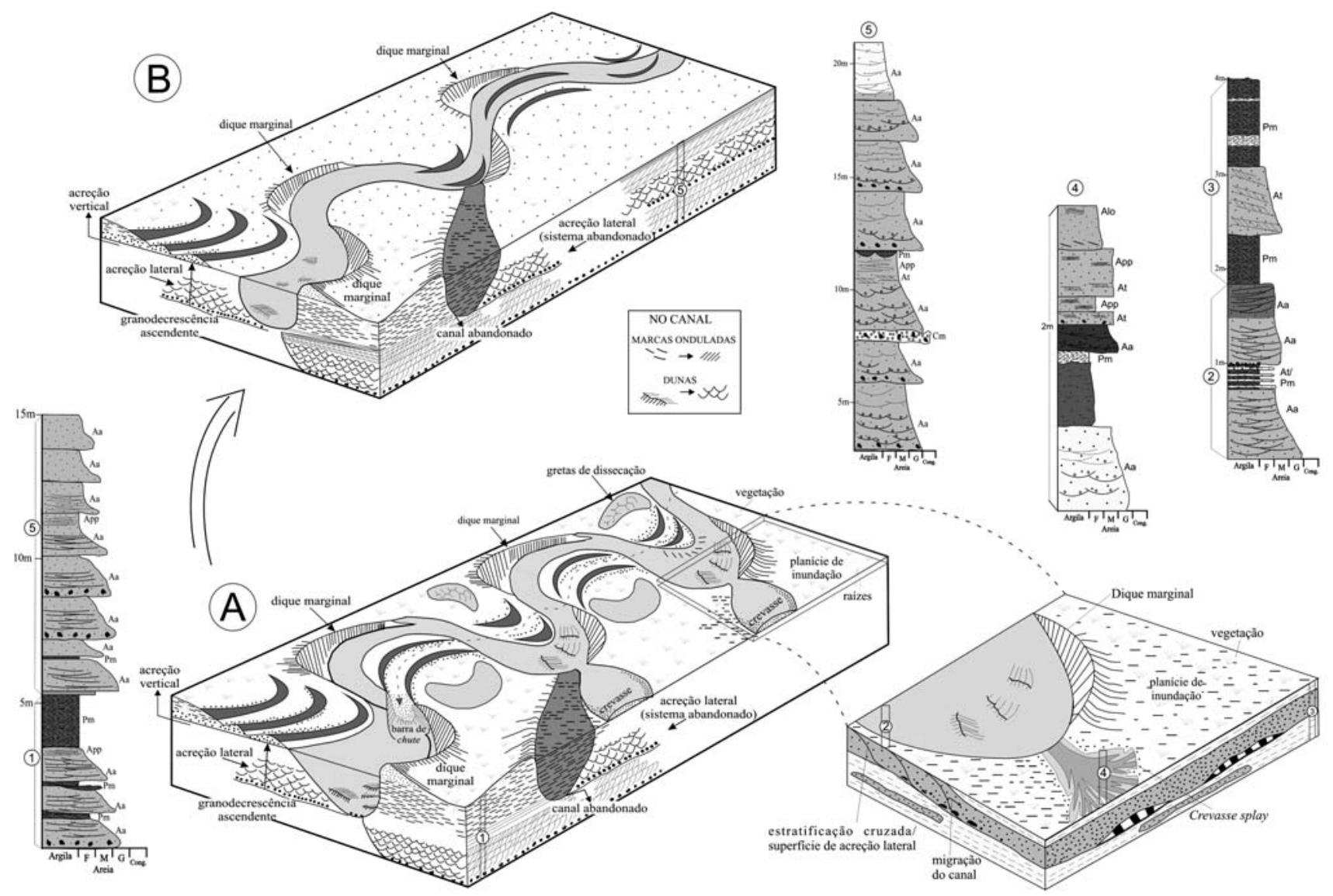

Figura 10 - Bloco diagrama do modelo deposicional proposto para Formação Alter do Chão, região de Óbidos - PA. A) Sistema meandrante com grande sinuosidade (parte inferior dos perfis) e B) Sistema meandrante pouco sinuoso (parte superior dos perfis). Para legenda ver figura 3. 
A baixa proporção de fácies pelíticas, na parte superior dos perfis, pode ser função de: 1) gradiente fluvial intermediário (uplift) impedindo maior acumulação de pelitos; 2) clima moderado a seco com pouca vegetação permitindo rápida migração do canal favorecendo, em menor proporção, a geração e deposição de argila.

CONCLUSÕES Os arenitos da Formação Alter do Chão, próximo à cidade de Óbidos - PA, foram depositados em um sistema fluvial meandrante com variação de sinuosidade (alta, na base dos perfis e baixa, no topo) e com carga mista (mixed-load). Essas características da Formação Alter do Chão podem ser comparadas com as do modelo fluvial 6 de Miall (1996). Foram reconhecidas sete litofácies (Cm, Aa, At, Al, $\mathrm{Pm}, \mathrm{Pb}$ e $\mathrm{Pd}$ ) organizadas em ciclos granodecrescentes ascendentes que variam de 1-6 m de espessura. A diversidade de estruturas sedimentares indica deposição sob condições subaquosas em regime de fluxo inferior enquanto gretas de dissecação estão relacionadas com exposições subaéreas. Análises de paleocorrentes indicam predomínio de fluxos unimodais com direções preferenciais para S/SW.

As litofácies foram organizadas em duas associações de fácies representadas por: preenchimento de canal, formado por barra conglomerática; formas de leitos arenosas e barra de acreção lateral e depósitos externos ao canal, formados por dique marginal, canal de crevasse e planície de inundação. Na associação de preenchimento de canal ocorre predomínio das fácies arenosas que se destacam nas partes superiores dos perfis estudados, enquanto os depósitos externos ao canal predominam as litofácies pelíticas, com destaque nas partes inferiores dos perfis.

Agradecimentos Os autores agradecem à Universidade Federal do Pará (UFPA) e à Universidade Federal do Amazonas (UFAM) pela infraestrutura fornecida, à Profa. Adriana Horbe (UFAM) pelo seu projeto que deu suporte a parte desse trabalho e ao Prof. Cláudio Lamarão (UFPA) pela ajuda com o microscópio eletrônica de varredura.

\section{Referências}

Allen J.R.L. 1970. Studies in fluviatile sedimentation: a comparison of fining upwards cyclothems, with particular reference to coarse member composition and interpretation. Jour. Sed. Petrol. 40:298-323.

Arnot M.J., Good T.R., Lewis J.J.M. 1997. Photogeological and image-analysis techniques for collection of largescale outcroup data. Jour. of Sedim. Res. 67:984-987.

Ashley G.M. 1990. Classification of large-scale sub-aqueous bedforms: a newlook at an old problem. Jour. Sed. Petrol. 60:160-172.

Aslan A. \& Blum M.D. 1999. Contrasting style of Holocene avulsion, Texas Gulf Coastal Plain, USA. In: Smith N.D. \& Rogers J. (eds.) Fluvial Sedimentology VI. Oxford, Blackwell, p. 193-209.

Bose P.K. \& Chakraborty P.P. 1994. Marine to fluvial transition: Proterozoic Upper Rewa Sandstone, Maihar, India. Sed. Geol. 89:285-302.

Boulangé B. \& Carvalho A. 1997. The bauxite of PortoTrombetas In: Carvalho A., Boulangé B., Melf A.J., Lucas Y. (eds.) Brazilian Bauxites. São Paulo, USP/FAPESP/ORSTOM, p. 55-73.

Bridge J.S. 2006. Fluvial facies models: recent developments. In: Posamentier H.,Walker R.G. (eds.) Facies Models Revisited. Tulsa, SEPM Society for Sedimentary, p. 85-170.

Brierley G.J. \& Ferguson R.J. 1997. What is a fluvial levee? Sed. Geol. 114:1-9.

Cain S.A. \& Mountney N.P. 2009. Spatial and temporal evolution of a terminal fluvial fan system: the Permian Organ Rock Formation, South East Utah, USA. Sedimentology, 56:1774-1800.

Cant D.J. \& Walker R.G. 1976. Development of a braided fluvial facies model for the Devonian Battery Point Sandstone, Quebec. Can. Jour. Earth-Sci. 13:102-119.

Cant D.J. \& Walker R.G. 1978. Fluvial processes and facies sequences in the sandy braided South Saskatchewan River, Canada. Sedimentology, 25:625-648.

Caputo M.V. 1984. Stratigraphy, tectonics, paleoclimatology and paleogeography of northern basins of Brazil. Tese de Doutorado, University of California, Santa Barbara, $583 \mathrm{p}$.

Caputo M.V. \& Rodrigues R.D.N.N. 1972. Nomenclatura estratigráfica da bacia do rio Amazonas. In: SBG, Cong. Bras. Geol., 26, Anais, p. 35-46.

Capuzzo N. \& Wetzel A. 2004. Facies and basin architectural of the Late Carboniferous Salvan-Dorénaz continental basin (Western Alps, Switzerland/France). Sedimentology, 51:675-697.

Collinson J.D. 1996. Alluvial Sediments. In: Reading H.G. (ed.) Sedimentary Environments and Facies, 3.ed. Oxford, Blackwell, p. 37-82.

Costa A.R.A. 2002. Tectônica Cenozóica e movimentação salífera na Bacia do Amazonas e suas relações com a geodinâmica das placas da América do Sul, Caribe, Cocos e Nazca. Dissertação de Mestrado, Instituto de Geociências, Universidade Federal do Pará, Belém, $238 \mathrm{p}$.

Cunha F.M.B., Gonzaga F.G., Coutinho L.F.C. Feijó F.J. 1994. Bacia do Amazonas. Bol. Geoc. Petrob., 8:47-55.

Daemon R.F. 1975. Contribuição à datação da Formação Alter do Chão, bacia do Amazonas. Rev. Bras. Geo. 5:58-84.

Daemon R.F. \& Contreiras C.J.A. 1971. Zoneamento palinológico da bacia do Amazonas. In: SBG, Cong. Bras. Geol., 26, Anais, p. 79-92. 
Dino R., Silva O.B., Abrahão D. 1999. Palynological and stratigraphic characterization of the Cretaceous strata from the Alter do Chão Formation, Amazonas basin. In: UNESP, Simpósio sobre o Cretáceo do Brasil and Simpósio sobre el Cretácico de América del Sur, 5, Anais, p. 557-565.

Eiras J.F, Becker C.R., Souza E.M, Gonzaga F.G., Silva J.G.F, Daniel L.M.F. 1994. Bacia do Solimões. Bol. Geoc. Petrob., 8:17-45.

Eiras J.F. \& Matsuda N.S. 1995. Roteiro Geológico do Paleozóico do rio Tapajós, borda sul da bacia do Amazonas, Pará. Belém, PETROBRÁS/E \& P - AM, Relatório interno.

Eiras J.F. 1998. Geology and petroleum system of the Solimões basin, Brazil. In: Rio'98 AAPG, International Conference \& Exhibition, Rio de Janeiro, Extended Abstracts, p. 446.

Halfar J., Riegel W., Walther H. 1998. Facies architecture and sedimentology of a meandering fluvial system: a Palaeogene example from the Weisselster basin, Germany. Sedimentology, 45:1-17.

Horbe A.M.C., Vieira L.C., Nogueira A.C.R. 2006. Geoquímica de camadas vermelhas bioturbadas da Formação Alter do Chão, Cretáceo da bacia do Amazonas. Rev. Bras. Geoc., 36:13-20.

Kraus M.J. \& Aslan A. 1999. Paleosol sequence in floodplain environments: a hierarchical approach. In: Thiry M. \& Simon-Coincon R. (eds.) Palaeo-Weathering, PalaeoSurfaces and Related Continental Deposits. Oxford, Blackwell, p. 303-321.

Leeder M.R. 1973. Fluviatile fining-upward cycles and themagnitude of palaeo-channels. Geol. Mag., 110:265-276.

Lucas Y. 1997. The bauxite of Juruti. In: A. Carvalho, B. Boulangé, A.J. Melf, Y. Lucas (eds.) Brazilian Bauxites. São Paulo, USP/FAPESP/ORSTOM, p. 107-133.

Mazumder R. \& Sarkar S. 2004. Sedimentary history of the Palaeoproterozoic Dhanjori Formation, Singhbhum, eastern India. Precambrian Res., 130:267-287.

Miall A.D. 1985. Architectural-element analysis: a new method of facies analysis applied to fluvial deposits. Earth Sci. Rev., 22:261-308.

Miall A.D. 1992. Alluvial deposits In: Walker R.G \& James N.P. (eds) Fácies models: response to sea level change. St. John's, Geological Association of Canada, p. 119-142.

Miall A.D. 1996. The Geology of Fluvial Deposits: Sedimentary Facies, Basin Analysis, and Petroleum Geology. New York, Springer-Verlag, 582 p.

Moura P. 1938. Geologia do baixo Amazonas. Rio de Janeiro, Serviço Geológico e Mineralógico, Boletim 91, 94 p.

Kistler P. 1954. Historical resume of the Amazon Basin. Belém, PETROBRAS/RENOR, Relatório interno 104-A.

Nepomuceno Filho F. \& Theodoro C.E. 1985. Evolução tecnológica e consequente aumento na resolução dos dados sísmicos na bacia do Amazonas. In: SBG, Simp. Geol. Amazônia, 2, Anais, p. 267-283.

Nogueira A.C.R., Vieira L.C., Suguio K. 1999. Paleossolos da Formação Alter do Chão, Cretáceo-Terciário da bacia do Amazonas, regiões de Presidente Figueiredo e Manaus. In: UNESP, Simpósio sobre o Cretáceo do Brasil and Simpósio sobre el Cretácico de América del Sur, 5, Anais, p. 261-266.

Petri S. \& Fúlfaro V.J. (eds) 1983. Geologia do Brasil (Fanerozóico). São Paulo, USP, 631 p.

Price L.I. 1960. Dentes de Theropoda num testemunho de sonda no estado do Amazonas. Anais da Acad. Bras. Ciên., 32:79-84.

Retallack G.J. 1988. Field recognition of palaeosols. In: J. Reinhardt, W.R. Sigelo (eds.) Palaeosols and Weathering Through Geological Time: Principles and Applications. London, Geol. Soc. Am. Spec. Publ., p. 1-20.

Rezende W.M. \& Brito C.G. 1973. Avaliação geológica da bacia paleozóica do Amazonas. In: SBG, Cong. Brasil. Geol., 27, Anais, p. 227-245.

Rossetti D.F. \& Netto R.G. 2006. First evidence of marine influence in the Cretaceous of the Amazonas basin, Brazil. Cretaceous Res., 27:513 528.

Rozo J.M.G., Nogueira A.C.R ., Carvalho, A.S. 2005. Análise multitemporal do sistema fluvial do Amazonas entre a ilha do Careiro e a foz do rio Madeira. In: INPE, Simp. Brasil. Sens. Rem., 12, Anais, p. 1875-1882.

Sharma M., Sharma S., Shukla K.U., Singh B.I. 2002. Sandstone body architecture and stratigraphic trend in the Middle Siwalik Succession of the Jammu area. India. J. Asian Earth. Sci., 20:817-828.

Smith N.D. 1970. The braided stream depositional environment: comparison of the Platte river with some Silurian clastic rocks: north-central Appalachians. Geol. Soc. Am. Bull., 81:2993-3041.

Turner P. (ed.) 1980. Continental red beds. Developments in sedimentology. Amsterdam, Elsevier, 562 p.

Turner B.R. 1993. Palaeosols in Permo-Triassic continental sediments from Prydz bay, East Antarctica. J. Sediment. Petrol., 63:694-706.

Truckenbrodt W., Kotschoubey B., Góes A.M. 1982. Considerações a respeito da idade das bauxitas na parte leste da região amazônica. In: SBG, Simp. Geol. Amazônia, 1, Anais, p. 201-209.

Van Houten F.B. 1973. Origin of red beds: a review 19611972. Rev. Earth Plant. Sci., 1:39-61.

Walker R.G. 1978. Facies models. Geo. Sci. Can. Rep. Ser., 1:171-188.

Walker R.G. 1992. Facies, facies models and modern stratigraphic concepts. In: R.G. Walker \& N.P. James (eds.) Facies Models - Response to sea Level Change. St. John's, Geological Association of Canada, p. 1-14.

Walker R.G. 2006. Facies models revisited. In:.W. Posamentier H.W. \& Walker R.G. (eds.) Facies Models Revisited. Tulsa, SEPM Society for Sedimentary, p. 1-17.

Wanderley Filho J.R. 1991. Evolução estrutural da bacia do Amazonas e sua correlação com o embasamento. Dissertação de Mestrado, Instituto de Geociências, Universidade Federal do Pará, Belém, 125 p.

Manuscrito ID 17011

Submetido em 11 de maio de 2010 Aceito em 07 de fevereiro de 2012 